\title{
Modelling, assessing, and ranking public procurement options for a climate-friendly catering service
}

\author{
Alessandro K. Cerutti ${ }^{1,3}$ - Fulvio Ardente ${ }^{2} \cdot$ Simone Contu $^{3} \cdot$ Dario Donno $^{1}$. \\ Gabriele L. Beccaro ${ }^{1}$
}

Received: 6 June 2016 / Accepted: 25 February 2017 /Published online: 24 March 2017

(C) The Author(s) 2017. This article is published with open access at Springerlink.com

\begin{abstract}
Purpose Several scientific papers and technical reports have discussed the role of green public procurement in the food sector. Different strategies for the restoration sector have been identified. However, there is not yet a common understanding of which policies could be the most efficient in reducing the global warming potential of the public restoration service. This paper assesses a set of procurement policies, ranking them according to their potential to reduce the greenhouse gas emissions of public catering.

Methods Eleven relevant green public procurement policies were identified from the literature. These are discussed in the context of a case study of the school catering service in the city of Turin (Italy). Initially, a life cycle approach is applied to a baseline scenario of the collective restoration system of the city, to quantify the quantity of greenhouse gases produced by the entire catering service (including all stages from the production of food to the management of waste from kitchens and canteens). Afterwards, the 11 policies were
\end{abstract}

Responsible editor: Matthias Finkbeiner

Electronic supplementary material The online version of this article (doi:10.1007/s11367-017-1306-y) contains supplementary material, which is available to authorized users.

Fulvio Ardente

fulvio.ardente@ec.europa.eu

1 Department of Agriculture, Forestry and Food Science, University of Turin, Turin, Italy

2 European Commission, Joint Research Centre, Directorate D. Sustainable Resources, Ispra (VA), Italy

3 Interdisciplinary Research Institute on Sustainability (IRIS), Turin, Italy applied to the baseline scenario so that the potential improvement achieved by each policy could be quantified.

Results and discussion The baseline scenario resulted in $1.67 \mathrm{kgCO}_{2}$ eq per average meal. The production of food dominates the global warming potential of the full service, being responsible for about $78 \%$ of the greenhouse gas emissions. Among the selected policies, a change in diet was the most effective (leading to a $32 \%$ reduction of the $\mathrm{CO}_{2}$ eq emissions), followed by the adoption of improved food production practices (11\% reduction) and the purchasing of certified green electricity (6\% reduction).

Conclusions The proposed method allows the assessment of procurement policies in the catering service by applying a simplified life cycle approach that considers all the stages of the process. Public authorities and other stakeholders could benefit from basing their decisions upon scientific evidence and avoiding the prioritisation of policies based on personal opinions or weak evidence. Uncertainties and areas for improvement in the method have been also identified for future investigation.

Keywords Carbon footprint · Energy efficiency · Environmental policies · Food policies · Green public procurement (GPP) · Life cycle assessment (LCA) · Sustainable diets · Waste management

\section{Introduction}

\subsection{Sustainability in the public restoration}

Eating is not just a biological act; it has many other meanings and repercussions. In the case of private food consumption, it is now widely recognised that eating is both an ecological and political act (Pollan 2006). Food labels are rich with 
information on food origin, quality, ethical issues, and environmental properties. New environmental product declarations (based on both international certification standards and environmental self-claims) are published every year, and consumers have started to factor the environmental impact of products into their choices (Vassallo et al. 2016). One such certification scheme, the Product Environmental Footprint (PEF), is currently under development by the European Commission (Galatola and Pant 2014).

Public food consumption is affected by different policy demands and competing interests (Lacourt and Mariani 2015). Food suppliers aim to make a profit from their collaboration with the public sector, which, on the other hand, aims to lower the cost of catering services as much as possible to reduce public expenditure. In 2012 in Europe, the 'food and catering service activities' sector involved more than 1.5 million enterprises, had a total turnover of approximately $€ 354$ billion, and employed 8 million people (Neto et al. 2016). Self-operating public bodies and contract caterers each have around a $50 \%$ share of the food and catering market, although this differs between member states and sector of society (FERCO 2012). In particular, in terms of the volume of meals provided, the 'business and industry' sector primarily uses private companies ( $85 \%$ in 2013) and the 'education' sector is dominated by public operating bodies (78\% in 2013; GIRA Foodservice 2014).

Because of the central role taken by the public restoration, there are generally three forces pushing for certain management practices, in particular (Barling et al. 2013): (I) political forces, including willingness to change, funding support, legislative viability, and international recognition; (II) social forces, such as the motivation for healthier food consumption and nutritional education; and (III) environmental forces, such as international agreements for the mitigation of climate change and national laws for the efficient use of resources. Such forces can converge on best practices that are usually defined as sustainable public procurement (SPP) (Smith et al. 2016). For example, the progressive reduction of meat consumption can satisfy both environmental and public heath pressures; however, the reduction of meat consumption could economically affect the livestock sector. Consequently, it is necessary to evaluate the economic, social, and environmental effects of different SPP practices. SPP practices encompass all three pillars of sustainability; when only the environmental aspects are considered, it is more correct to refer to green public procurement (GPP) (Smith et al. 2016).

There are several different GPP policies that can be applied to all phases of the catering process, ranging from specifying particular cultivation practices up to the management of waste (Chandler et al. 2015). A recent EU report on the topic (Neto et al. 2016) describes the opportunity to include GPPs in food provisioning (concerning e.g. the purchasing of organic food products, marine, and aquaculture food products, seasonal products, animal welfare, types of packaging, and use of sustainable oils), food transport, menu planning, and type of consumables used (e.g. paper products, tableware, and cleaning products, waste sorting and disposal). Interestingly, Neto et al. (2016) identified several studies that analysed the improvement in the environmental impact of different aspects of food production and supply chain, although these studies mainly focused on the environmental performance of a single specific aspect (e.g. just agricultural production practices, transport issues, or the impact of material production). However, the literature lacks studies that investigate the environmental performance of GPP policies for the catering service.

\subsection{Aims of the article}

This article adopts a different perspective to previous research applied to the catering sector. It aims to answer to the following research question: how should the GPP practices that a municipality can adopt be assessed to determine the best way to improve the climate performance of the catering service? This includes different aspects such as diets, food storage, cooking, serving options, and waste management.

The article focuses on the analysis of several policy options for the catering service that, compared to the current practices, may be the most effective in terms of reduction of greenhouse gas $(\mathrm{GHG})$ emissions. The aim of this research is to rank the best performing GPPs for the sector, in order to provide scientific guidance to public administrations and suppliers.

The research method developed for the comparison of the different procurement options is illustrated in Section 2. Section 3 presents the application of this method to the case study of the school catering service of the city of Turin (Italy). Next, Section 4 describes the different policy options, chosen from the scientific and technical literature or proposed by stakeholders from the Municipality of Turin, and assesses the potential for reduction of GHG emissions. Based on these assessments, specific and general recommendations are provided in Section 5, together with the discussion of key issues related to the adoption of the proposed policies.

\section{Method applied to test and rank the GPP options}

\subsection{Environmental assessment of collective restoration}

Although the scientific and technical literature concerning GPP in the food sector is quite rich with case studies, quantitative environmental assessment is applied in very few cases (Cerutti et al. 2016). Furthermore, most recent documents on GPP by the European Commission (European Commission 2011) consider environmental criteria based not on threshold values of the environmental impact indicators but rather on qualitative judgements of practices, such as the seasonality of 
products, harvesting practices, minimisation of waste and packaging, and professionalisation of operators (European Commission 2011). However, if sustainability practices are not associated with a specific evaluation of the environmental performances (such as the emission of GHGs, water depletion, or soil consumption), it is not possible to quantify the actual environmental savings (Cerutti et al. 2016). Because of the complexity of the public restoration service, the evaluation of its environmental performance is not straightforward. Only a few studies apply an environmental impact assessment method, such as life cycle assessment (LCA) or derived footprints, so it is very difficult to rank the relative impact of the different GPP practices.

A recent publication by Caputo et al. (2014) focused on the evaluation of self-sufficiency in catering for public schools, focusing on the region of Lombardy (Italy) to assess the surface required to fully sustain the provision of food. The authors did not illustrate the assessment method and results in detail, other than introducing a tool called the 'Food Chain Model', used to verify self-sufficiency and provide policy suggestions without a quantification of the environmental relevance.

Another important study focusing on the methodological issues for the application of the LCA to a catering service (public or otherwise) in Switzerland was published by Jungbluth et al. (2016). This used an organisational LCA approach to model the potential environmental impacts of the service. Results obtained in the assessment therefore covered the full catering service, but only the environmental improvement achievable by the procurement of seasonal food was tested as one among several options for greening the service. One of the results discussed in the paper was that the catering service in the case study emitted about three times less GHGs than having the same meal prepared at home. This result is in line with Sturtewagen et al. (2016), who compared the resource consumption of a specific catered pork-based meal with an identical meal cooked at home, resulting in 15-40\% higher impacts.

In the context of private collective restoration, another interesting LCA application was developed by Pulkkinen et al. (2016), which focused on the assessment of the environmental performance of restaurants. In this research, the criteria for a greener meal were created based on a discussion with three restaurant operators in Finland and on a simplified carbon footprinting method based on the production of raw materials. One of the main purposes of calculating the environmental performance of restaurants is to create certifications so that marketing leverage may be applied, as described in detail by Baldwin et al. (2011). In these case studies, authors conducted life cycle assessment research on restaurants and food service operations to define priorities for environmental improvement, and the results were used to develop sustainability standards and ecolabel programs. The reduction of environmental impacts of catering services managed by private and public authorities may provide an example for other sectors and for the whole of society.

As already highlighted, the majority of previous research has only considered specific issues or partial stages of catering services instead of the catering system as a whole. In fact, several studies are limited just to the analysis of the transport of food. Some authors studied the provisioning part of the system, for example Bortolini et al. (2016), who investigated the operating costs, carbon footprint, and delivery time goals of fresh fruits and vegetables provided by a set of Italian producers to several European retailers. Other studies specifically investigated the impact of refrigerated transport, such as Chen and Hsu (2015), who calculated the GHG emissions of two freight transport systems by modelling the delivery scheduling for the time-dependent demand of multi-temperature foods and by considering both emissions from energy consumption and refrigerant leakages into the environment. The maintenance of proper temperatures in food preservation, for both cold chain and warm food, can be a relevant environmental hotspot. Fusi et al. (2016) calculated the environmental performance of two catering approaches: cook-and-serve (food is cooked and immediately served to consumers) and deferred (cook-warm and cook-chill), which allowed the decoupling of the production of food from its consumption.

Another aspect of transport in the food sector which is frequently investigated is the relative weight of the distance from the production site to the markets (the so-called food miles). For example, Rothwell et al. (2015) evaluated tradeoffs between distances and agricultural technologies for lettuce produced close to Sydney, using the footprint family indicator (carbon footprint, land use, water use, and eutrophication) with an LCA-based approach.

\subsection{Description of the research method}

The current study is divided into two phases: the first is the quantification of a baseline catering scenario, in which the environmental impacts are quantified; the second phase concerns the calculation of the potential impact reductions related to each specific GPP policy and their comparison with the baseline scenario. Thus, each GPP policy can be associated with a reduction share and can be ranked to determine which is the most effective.

Although several environmental impact indicators are currently available in the scientific literature, this article focuses exclusively on the climate change impact based on the quantification of the GHG emissions. The use of a single impact indicator has both benefits and limitations (Weidema et al. 2008; Finkbeiner 2009). As the main aim of this research is to test a method for GPP performance evaluation, carbon footprinting $(\mathrm{CF})$ offers the opportunity of having a simplified 
and practical indicator to be used especially when a large number of items must be assessed in a short time frame. Because it is a simple but robust account framework, it also offers the potential to introduce life cycle approaches into organisations and decision-making contexts that pure LCA has not yet reached (Finkbeiner 2009).

Three main reasons can be given for the relevance of accounting for GHG emissions in the environmental assessment of GPP policies:

- Climate change is one of the greatest challenges facing nations, governments, businesses, and citizens and will influence the way we live and work in future decades (IPCC 2007). Climate change is subject to the continuous attention of and monitoring by policy makers at every level, with industries and citizens being highly sensitive to these issues (Ostrom 2009).

- Climate change reduction efforts have been agreed globally, and specific targets have been enshrined in international treaties, such as the Kyoto protocols (UNFCCC 1997), and translated into national legislation (e.g. the national law no. 120 of 2002 in Italy). These international agreements also affect local authorities. The achievement of national targets is based on specific planning and actions undertaken at the local level.

- The global warming potential (GWP), used to assess climate change, is recognised by the scientific community, and in particular by LCA experts, as one of the most robust environmental indicators currently available (JRC 2010). The GWP incorporates all the GHGs, weighted according to their global warming potential and expressed as an equivalent amount of carbon dioxide $\left(\mathrm{CO}_{2} \mathrm{eq}\right)$. For this reason, the calculation of GWP is generally referred to as carbon footprinting $(\mathrm{CF})$.

Furthermore, several international organisations have developed $\mathrm{CF}$ standards in the last decades, for examples the ISO standards 14067 on the carbon footprint of products (ISO 2013), the GHG Protocol developed by the World Resources Institute and the World Business Council on Sustainable Development (WRI and WBCSD 2001), and the British publicly available specification PAS 2050 to assess the life cycle GHG emissions of goods and services (BSI 2011).

Further to the benefits of using a single impact indicator, there are also several limitations. Concerns have been raised about oversimplified methods that may mislead stakeholders about the environmental implications of products and services (Finkbeiner 2009) as well as offering an incomplete picture of the impacts in certain cases compared to a multiple-indicator approach (Weidema et al. 2008).

As described in depth by Laurent et al. (2012), several product categories show a poor correlation between $\mathrm{CF}$ and other impact categories, such as toxicity-related impacts or resource depletion, because of the different sources of impacts in the life cycles of food (including waste management). In fact, one of the most critical issues related to applying just $\mathrm{CF}$ is the so-called burden shifting of environmental impacts from one sphere to another, especially when comparing different product life cycles (Fang et al. 2014). Environmental impacts other than the CF can be more important when assessing the sustainability of agricultural products: eutrophication, acidification, ecotoxicity and human toxicity, biodiversity, and water use can all be important (Guinee et al. 2010). Furthermore, the $\mathrm{CF}$ is not considered to be one of the most urgent pressures in relation to the planet boundaries, as other impact categories might have already posed a critical danger to the ecosystem (Fang et al. 2015; Sala et al. 2016).

The limitations of using a single indicator may become even more relevant when applied in a decision-making context (Laurent et al. 2012). This is because corporations and authorities often aim for simplicity-using tools for which data are readily available and whose results are potentially intelligible to a large audience of stakeholders (including tenderers and citizens). This pressure is reflected in the risk of developing policies solely relying on these indicators and not considering the risk of burden shifting.

The selection of the $\mathrm{CF}$ as a reference impact category was agreed with the local authority (city of Turin) with whom the present research method has been tested. This decision was taken because the accounting of GHG emissions was judged as potentially intelligible by a larger audience of local stakeholders (including suppliers and citizens) and in line with the objectives of the administration to reduce the GHG emissions of the municipality.

Contrary to the common approach of collecting data from a sample of facilities (Caputo et al. 2014) or considering just a single type of meal (Pulkkinen et al. 2016) or food product (Bortolini et al. 2016), the research presented here investigated the full catering service of the schools of the city of Turin.

For the quantification of the baseline emission scenario (first phase), a modular approach (Cerutti et al. 2014a) was applied to divide the full catering service into relevant functional blocks and to simplify the modelling of the system. Four modules (food production; food transport; cooking, storage, and serving; and waste management) were identified and studied separately. Impacts have been calculated for an average meal, which was chosen as the functional unit for the entire study.

The research method applied for the quantification of the baseline emission scenario is shown in Fig. 1. The starting point is the analysis of the main menu of the service. The frequency of different foods in the menu over 1 year is calculated in order to define the average meal, composed of a fraction of different foods. Each food is then associated with a proxy food item. For example, in the case of fruit, an apple was chosen as the reference proxy because it was the most 


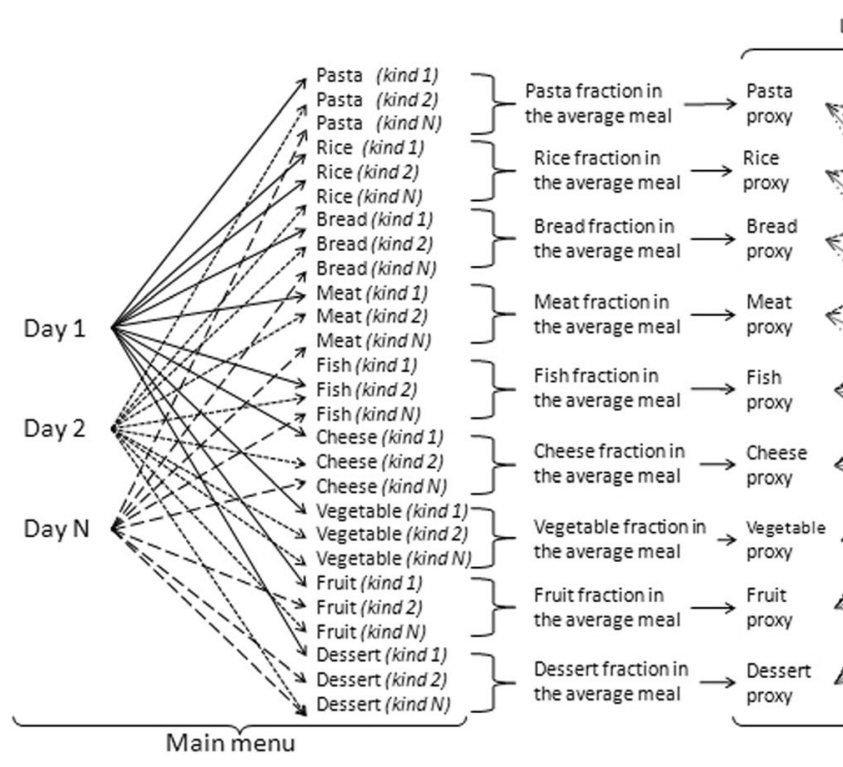

Fig. 1 Summary of the method used for setting the baseline scenario (phase 1). Starting from the main menu for each school level, an average meal is calculated according to the frequency of each food type. Then each food type is associated with a proxy food item

consumed fruit for the school year 2013/2014. The use of food proxies, instead of the actual food items that are consumed, has strengths and weaknesses. The use of proxy products has been applied in several consumption-oriented LCA studies to specifically assess the impacts of certain representative foods consumed in a specific region (Notarnicola et al. 2017). For example, Muñoz et al. (2010) assessed annual Spanish food consumption based on LCA studies available in the literature on food proxies for Spanish food purchased by households, catering, restaurants, and institutions. More recently, Eberle and Fels (2016) assessed the environmental burden of food consumption and food losses in Germany by considering the average German food basket and by using 23 food proxies as representatives of eight food categories (e.g. apples, oranges, and bananas were identified as a representative of the product group 'fruits'). Eberle and Fels (2016) selected some proxies for their study based on their share of the product group and on data availability. Furthermore, in Notarnicola et al. (2017), a basket of food products was identified as a representative of average European food and beverage consumption, in order to assess the environmental impacts of food consumption in Europe. According to Notarnicola et al. (2017), the selected food proxies reflected the relative importance of the products in terms of mass and economic value. Moreover, proxy products are also used in studies combining 'bottom-up' and 'topdown' assessment methods, such as hybrid input-output LCAs (Pairotti et al. 2015). In hybrid approaches, the use of proxy products allows some of the possible problems arising from truncation errors of LCAs (especially when applied to consumption), and the non-specific nature of the data of inputoutput analysis, to be overcome.
LCA databases and technical literature

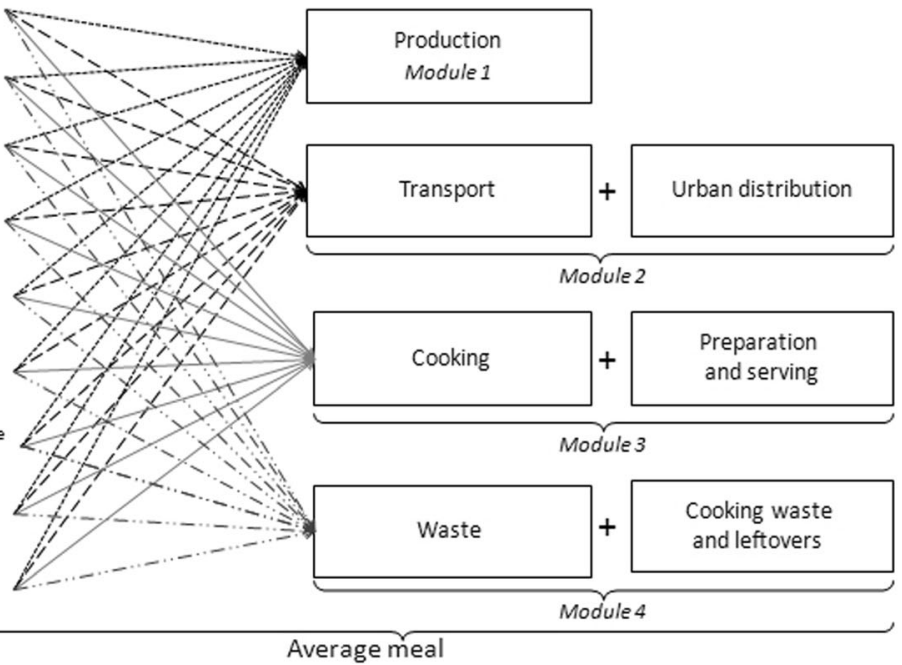

available in LCA databases or technical literature, and information for the four modules is extracted. Data from the literature have been complemented by primary data to calculate the impacts of the average meal

In the present study, for each food proxy, a life cycle inventory (LCI) was built based upon several literature sources. To achieve consistent and comparable inventories, a prioritisation of the sources was adopted: at first, environmental product declarations (EPDs) of Italian products were chosen, when available; if not available, LCI were built on data from Italian studies published in scientific journals; when this was not possible, European case studies published in scientific journals were chosen. The full list of sources for the construction of the LCIs of the proxy food is available in the Electronic Supplementary Material (Table SM01). In some cases, several studies on products from the same food categories were available, making it difficult to choose the most representative reference LCI. In these cases, a new proxy product was built by calculating an average value of the LCIs available. This approach allows the variability of the emission intensities of different products belonging to the same food category to be included.

The LCIs have been based on data from the literature and include all processes in the life cycle of proxy products (therefore adopting a 'cradle-to-grave' perspective). Available data were also associated with the different modules. For example, in the case of the LCI of pasta, data about the agricultural phase was allocated to module 1 , data about the transport of the final product to module 2, data about cooking to module 3 , and data about the production of primary and secondary packaging to module 4.

Data available from the literature represented the main input to build the LCI of proxy products. However, primary data were also used to complement the LCI of modules 2, 3, and 4 (see Section 3.1 for details on primary data collection). Direct 
data on fuel consumption in local urban distribution was used to complement the LCI of module 2, primary data on the consumption of materials and energy in kitchens and schools were used for the LCI of module 3, and direct data on waste management were used for module 4 . The development of the LCI of proxy products is summarised in Fig. 1.

The GWP of each proxy food was calculated by using emission factors from ILCD 2011 (in particular climate change; midpoint; GWP100; IPCC 2007), determining the impacts for the different modules separately. The contribution of each food proxy to the LCI of each module was calculated in proportion to the occurrence of the proxy in the average meal (Fig. 1).

For the evaluation of different GPP policy options (second phase), a literature review was conducted to discover the most commonly used GPP policies in the catering sector, with a special focus on school services. Both scientific and technical papers, as well as reports, were identified through Google Scholar and web search engines. Once the most common GPP policies were identified, the CF reduction due to them each was quantified and compared to the baseline scenario to calculate the reduction share. GPP policies have therefore been ranked in terms of the absolute effectiveness and relative CF reduction.

\section{The baseline emission scenario for the school catering service in Turin}

\subsection{Description of the school catering service and definition of the baseline scenario}

The full school catering service of the city of Turin includes 170 institutes, serves approximately 54,200 pupils between the ages of 0 and 13 years, and delivers approximately 8 million meals per year with a total value of approximately 40 million Euros. School catering represents a significant component of the procurement budget for the municipality, which is interested in increasing the efficiency of the service. With this aim in mind, the city of Turin participated to the INNOCAT project (Procurement of eco-innovation in the catering sector), ${ }^{1}$ funded by the European Commission and coordinated by ICLEI (Local Governments for Sustainability). Within this project, local authorities introduced several measures and included various criteria for their catering contracts with the aim of reducing the associated CF. Some of the measures adopted by the INNOCAT project are considered within the GPP policy options for the analysis.

The main data for the baseline scenario of the school catering service of the city of Turin were collected for the

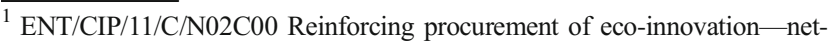
work of green public and private procurers
}

school year 2013/2014. Data related to food consumption, meals served, electricity used, and waste generated were also collected for this year. However, because the GPP policies of the INNOCAT project were implemented that year, other data for the baseline scenario (food miles from provisioning and urban distribution, percentage of organic food, use of tap water) are collected considering the previous year, when no specific GPP policies had been adopted.

A key aspect of the analysis is the definition of the menu. The meal always constitutes of one starter (usually based on pasta, rice, or soup), a main course for protein intake (e.g. meat, fish, omelette, cheese, or protein-rich vegetables), a dish containing vegetables (fresh or cooked), and dessert (usually fruit, yogurt, sweets, or box of fruit juice). During the reference year, pupils were free to choose one of four menus: (I) a standard menu, which includes meat and fish; (II) a meat-free menu, in which meat-based meals are substituted with fish, eggs, cheese, or protein-rich vegetables; (III) a vegetarian menu, in which fish and meat are substituted with eggs, cheese, or protein-rich vegetables and (IV) a gluten-free menu, in which a special wheat is used for the preparation of pasta and pasta-based dishes (such as lasagne). In the baseline scenario, the standard menu was chosen as a reference for all schools, and alternative menus II and III were tested as possible options for greening the catering service.

For the case study, the average meal of the baseline scenario is calculated based upon the standard menu during the school year 2013/2014 in the first grade of the secondary class. The quantity of each food item in the average meal is calculated as a proportion of the quantity of the same food consumed in the reference year. The composition of the average meal is presented in Table 1 .

Each food item within the standard menu is associated with a proxy product. For each proxy food item, a simplified LCA is carried out by considering the most common production practices according to technical references, scientific literature (e.g. Notarnicola et al. 2015), and environmental product declarations. The simplified LCAs use a farm-to-plate approach and therefore include emissions from production, transport, cooking, and waste from packaging. These emissions are used to estimate the impacts of the four modules specified below. Primary data are used to complete the emission calculation of each module, as described in the following sections.

Module 1: food production This module consists exclusively of the GHG emissions from the production phase of each proxy food item's LCA. The module includes all agricultural practices and the production of all agricultural inputs including fertilisers and pesticides, as well as electricity from the national power grid, water management, and machinery use.

Module 2: food transport This module contains the impacts of food transportation. It consists of two different phases: (a) 
Table 1 Calculation of the quantity of each food item in the average meal to be used in the baseline scenario. The quantity of each food is calculated according to the overall fraction of its occurrence in the standard menu of the secondary class, first grade, for the school year 2013/2014

\begin{tabular}{|c|c|c|c|c|c|}
\hline Food item & $\begin{array}{l}\text { Average quantity in } \\
\text { standard portions }\end{array}$ & Unit & $\begin{array}{l}\text { Frequency in the } \\
\text { average meal }\end{array}$ & $\begin{array}{l}\text { Quantity in the } \\
\text { average meal }\end{array}$ & Unit \\
\hline Pasta & 70 & $\mathrm{~g}$ & 0.6 & 42 & $g$ \\
\hline Rice & 70 & g & 0.25 & 17.5 & g \\
\hline Soup & 35 & $\mathrm{~g}$ (of pasta/rice) & 0.15 & 5.25 & $\mathrm{~g}$ (of pasta/rice) \\
\hline Sauce & 80 & $\mathrm{~g}$ & 0.9 & 72 & $\mathrm{~g}$ \\
\hline Tuna & 80 & g & 0.1 & 8 & g \\
\hline Other fish & 140 & g & 0.1 & 14 & g \\
\hline Egg/omelette & 110 & g (of omelette) & 0.1 & 11 & $\mathrm{~g}$ (of omelette) \\
\hline Cheese & 80 & g & 0.1 & 8 & $\mathrm{~g}$ \\
\hline Mozzarella cheese & 90 & $\mathrm{~g}$ & 0.1 & 9 & g \\
\hline Beef & 90 & $\mathrm{~g}$ & 0.15 & 13.5 & g \\
\hline Pork & 90 & g & 0.15 & 13.5 & g \\
\hline Turkey & 100 & g & 0.1 & 10 & g \\
\hline Other poultry & 100 & g & 0.1 & 10 & g \\
\hline Cooked vegetables & 150 & g & 0.7 & 105 & $\mathrm{~g}$ \\
\hline Fresh vegetables & 50 & g & 0.3 & 15 & g \\
\hline Fruit & 140 & g & 0.55 & 77 & g \\
\hline Yogurt & 125 & g & 0.35 & 43.75 & g \\
\hline Fruit juice & 200 & $\mathrm{ml}$ & 0.05 & 10 & $\mathrm{ml}$ \\
\hline Dessert & 100 & $\mathrm{~g}$ & 0.05 & 5 & g \\
\hline Bread & 60 & g & 1 & 60 & g \\
\hline
\end{tabular}

the provisioning phase, which includes the transport of goods from the production sites to the local hubs (located on the outskirts of Turin for city distribution), and (b) the distribution phase, which includes the transport of the food from the periurban city hubs to the school canteens.

For the provisioning phase, the supply structure (geographical origin and freight requirements for conservation) of each proxy food item is described so that the average mileage per transport mean of the food may be obtained. Data regarding the supply structure, collected from the Italian database of food production and consumption, is used (Agri ISTAT 2015).

The baseline data used here (including transport quantities, distances, and modalities) were collected from the suppliers that were contracted by the city of Turin for the school years 2013/14. This includes the suppliers' registry of deliveries, which is a schedule of all the deliveries made by each van, including timing, route, food block delivered, and the type of fuel used. The distribution of food is divided into three blocks: (I) 'prepared meals', which includes warm dishes (e.g. pasta and meat); (II) 'cold food', which includes food that is prepared in the schools (e.g. salad, cheese, dessert); and (III) 'fruit', which includes exclusively fresh fruit that can be simply served. The average mileage per fuel type is calculated for the three distribution blocks, and each proxy food item is assigned to a specific distribution block.
Module 3: cooking, storage, and serving This module focuses on all activities of the kitchens and canteens: food storage in refrigerators and freezers, cooking and preservation in specific containers, heating or re-heating in schools, and serving. Emissions from the consumption of electricity, natural gas, and water in the peri-urban hubs and school canteens are accounted for. The GHG emissions from the life cycle of cleaning products and cooking appliances are also considered. Data were collected in the three major cooking hubs via the use of a questionnaire and technical visits. For this module, the entire emissions for the school year 2013/2014 are accounted for and divided by the number of meals delivered to the canteens, to estimate the CF of a single meal.

Module 4: waste management Waste can be produced during all phases of the catering process and is very dependent on several consumption behaviours (Falasconi et al. 2015). The quantification of waste is not always straightforward and must be modelled according to the needs of the study. In the context of public restoration, the waste that is produced during the agricultural and logistical phases cannot be a target for GPP policies. However, the waste produced in the cooking and consumption stages can be easily monitored and reduced. Consequently, this module does not include waste generated in the phases described by modules 1 and 2, but it includes all 
waste that is generated in the cooking, serving, and eating (or leftovers) of food, as well as in cleaning. Data on such issues were collected in different ways: data on waste produced within the kitchens were collected in the three major cooking hubs via the use of a questionnaire and technical visits; data on waste produced in the school were modelled according to each serving option adopted in the schools; and data on leftover food were acquired by a specific survey conducted by the city of Turin, within the context of another project called 'Create your menu!'2 in which students were asked to design their menu in order to tailor meals to their preferences and to consequently reduce leftovers. Regarding serving, different schools in the city adopted different options according to their needs, for example the use of disposable tableware, washable dishes, or compostable dishes and the use of tap water or bottled water. To be able to properly evaluate the impact of GPP policies on waste, it was assumed that in the baseline scenario, waste is handled according to current practices, without employing procedures for waste mitigation. Good practices that already take place in some schools are considered as potential improvements in Section 4 of this paper.

\subsection{CF of the baseline scenario}

The quantification of the climate change potential of the baseline scenario described in the previous section is presented in Fig. 2. The climate change potential of the average meal of the baseline scenario is $1.67 \mathrm{kgCO}_{2}$ eq. Module 1 (the production phase) dominates the potential impact with $78 \%$ of the CF of the full catering service. The main component of the $\mathrm{CF}$ of this module derives from the main course (79\% of the CF of the module and $61 \%$ of the CF of the full service). Specifically, this can primarily be attributed to the meat component of the average meal (51\% of CF of module 1 and $39 \%$ of the CF of the full service).

The other three modules play minor roles in the determination of climate change potentials; in terms of the proportions of the total CF of the service, food logistics (module 2) accounts for $3 \%$, food handling (module 3 ) accounts for $8 \%$, and waste (module 4 ) accounts for $11 \%$. Besides food production, another relevant single point of emissions is due to the electricity consumption in the cooking facilities and school canteens (6\% of the $\mathrm{CF}$ of the catering service).

The results of the baseline scenario presented here are significantly different than the results of Jungbluth et al. (2016) in which the $\mathrm{CF}$ of an average meal served in a canteen operated by the SV group was about $4.1 \mathrm{kgCO}_{2}$ eq. Nevertheless, the partitioning of the impacts between different parts of the service in both studies is similar. In fact, according to Jungbluth et al. (2016), the agricultural phase is responsible for $58 \%$ of

\footnotetext{
$\overline{2}$ Translated from the original Italian title: 'Il menù l'ho fatto io!' (Provincia di Torino 2013)
}

the $\mathrm{CF}, 24 \%$ is due to operations at the canteens (e.g. the use of water and electricity, as well as disposal of food waste), and $8 \%$ can be attributed to cooking, $4 \%$ to packaging, and $6 \%$ to the transport from farm to the canteens. The relative impacts of meat are also similar in the two studies: in Jungbluth et al. (2016), meat is responsible for $48 \%$ of the CF of the agricultural phase, while $10 \%$ is related to dairy products and $8 \%$ to fresh vegetables.

\subsection{Sensitivity analysis}

Variability can affect food LCA studies mainly because of the biological nature of the production systems and the correlation with local conditions and climatic events (Notarnicola et al. 2015). Nemecek et al. (2012) estimated that the variability in the global warming potential of the most common crops can significantly affect the results, ranging from 8 to $41 \%$ of the GWP per kilogram of the final product. It is therefore necessary to identify the variability of inventory data of the study and to evaluate how sensitive the results are to these assumptions.

In the investigated systems, each module presents some critical sources of variability. In the production phase, a larger amount of uncertainty is associated with yield because it can vary due to differences in the geographical areas (different climatic conditions), genetic issues (different cultivars), and slightly different agricultural practices within the same production protocol (as applied by different farmers). Several studies (Cellura et al. 2012; Hayashi 2013; Nemecek et al. 2005; Perrin et al. 2014) remark that the yield of an agricultural system plays a pivotal role in the quantification of the environmental impacts of such systems. First, there is a physical relation between the quantity and quality of the yields and the amount of inputs (e.g. materials and energy) and externalities (e.g. emissions) of the agricultural practices. Furthermore, the environmental impacts are related to the yield, because of the use of a mass-based functional unit in the LCA of food. Relatively small variations in yields can significantly affect the results and, consequently, their interpretation (Cerutti et al. 2014b). Therefore, variations in the yield of each proxy food item should be considered in the assessment of the variability of the production phase. Based on the data collected from agricultural manuals (VV. AA. 1997), food LCA reviews (e.g. Notarnicola et al. 2015), and other broad studies in food LCAs (e.g. Nemecek et al. 2012), the following average variation ranges of the yields are assumed $\pm 15 \%$ for cereal products (pasta, rice, and bread); $\pm 10 \%$ for products from animals (meat, cheese, and eggs, but excluding fish due to a lack of available data); and $\pm 20 \%$ for vegetables and fruits. With the application of these yield variation ranges in the LCIs of food proxies, it was possible to calculate the standard deviation of $\mathrm{CF}$ values of each proxy (Table 2). 
Fig. 2 Breakdown of $\mathrm{CF}$ in the four LCA modules for the average meal in the baseline scenario

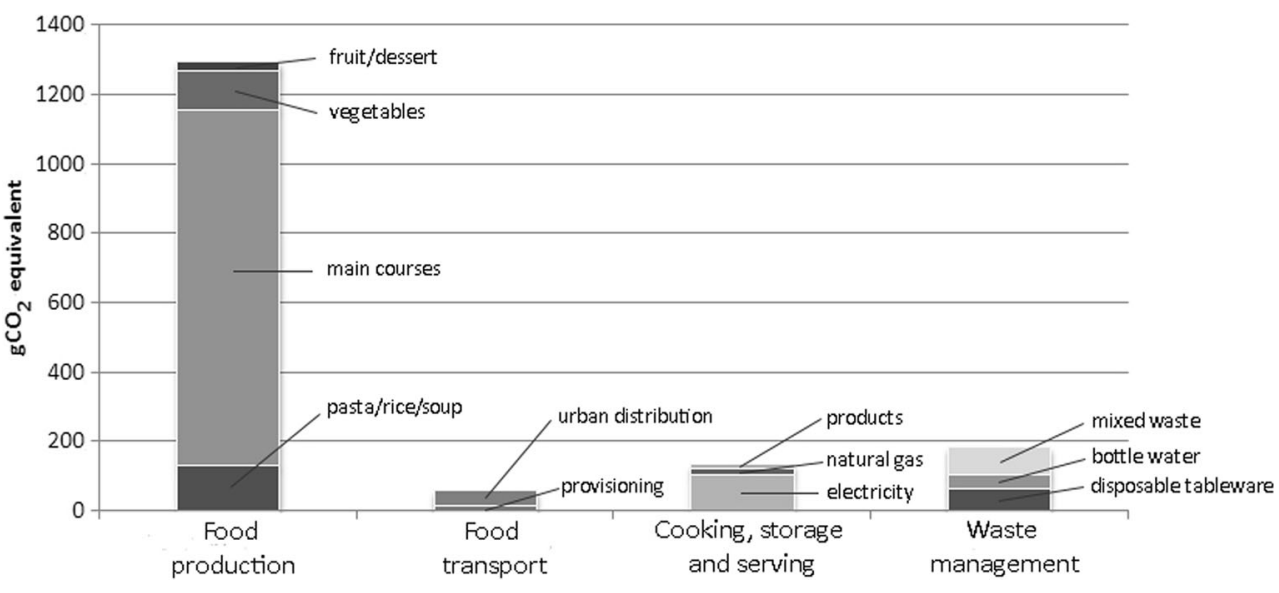

The resulting standard deviations are comparable with values found in the meta-analysis performed by Clune et al. (2016) for most of the food categories, apart from meat from ruminant livestock $\left(2.15 \mathrm{kgCO}_{2} \mathrm{eq} / \mathrm{kg}\right.$ of meat in this study and $12.47 \mathrm{kgCO}_{2} \mathrm{eq} / \mathrm{kg}$ meat in Clune et al. 2016). However, the review by Clune et al. (2016) analysed the CF of studies from all over the world, with very different pasture practices, and this explains the higher variability compared with results from single country.

Table 2 Carbon footprint (CF) in module 1 for each conventional food item considered. $\mathrm{CF}$ values are expressed as $\mathrm{kgCO}_{2}$ eq per $\mathrm{kg}$ of food item and $\mathrm{gCO}_{2}$ eq per standard portion. The standard deviation of the $\mathrm{CF}$ values of conventional product proxies (due to the variations of the yield in the LCIs for the sensitivity analysis) is also reported

\begin{tabular}{llll}
\hline Food Item & $\mathrm{kgCO}_{2} \mathrm{eq} / \mathrm{kg}$ & $\mathrm{St} . \mathrm{dev}$ & $\mathrm{gCO}_{2}$ eq/portion \\
\hline Pasta & 1.05 & 0.16 & 73 \\
Rice & 1.34 & 0.23 & 94 \\
Soup & 2.26 & 0.36 & 79 \\
Sauce & 0.59 & 0.07 & 47 \\
Tuna & 13.58 & na & 1086 \\
Other fish & 3.12 & na & 436 \\
Egg/omelette & 1.78 & 0.17 & 196 \\
Cheese & 12.64 & 1.39 & 1011 \\
Mozzarella cheese & 10.04 & 0.90 & 904 \\
Beef & 19.47 & 2.15 & 1752 \\
Pork & 15.89 & 2.04 & 1430 \\
Poultry & 5.19 & 0.70 & 519 \\
Cooked vegetables & 0.79 & 0.17 & 118 \\
Fresh vegetables & 1.91 & 0.43 & 95 \\
Fruit & 0.14 & 0.03 & 19 \\
Yogurt & 0.18 & 0.04 & 22 \\
Fruit juice & 0.51 & 0.10 & 102 \\
Dessert & 2.12 & 0.50 & 212 \\
Bread & 1.37 & 0.13 & 82 \\
\hline
\end{tabular}

na not applicable
The main source of variability in the logistical phase is the distance travelled by trucks during the provisioning phase. Assumptions concerning the distance between the national food hubs and the city of Turin have a low variability. On the other hand, local transport between farms and the regional hubs of each nation are more uncertain. Consequently, we assumed a variation of $\pm 20 \%$ of the distances travelled from the farms to the hubs of Turin, in the case of international suppliers, and a range of $\pm 10 \%$ in the case of national and regional supply chains. Additional variability can affect the distribution phase in the urban area. An average speed of $25 \mathrm{~km} / \mathrm{h}$ has been assumed as a reference for the calculation of the emissions of the vans. However, an increase of $10 \%$ in the emissions during the distribution has been assumed, to allow for the potential variability of the traffic.

Cooking, storing, and serving (module 3 ) are the phases characterised by the lowest variability, since data are collected directly at the facilities on an annual basis. The input data are annual averages, so they already include the variability in the consumption of electricity, natural gas, and water by the appliances. Nevertheless, in order to account for potential variability over different years, a variation of $\pm 4 \%$ is assumed for electricity consumption, $\pm 20 \%$ for natural gas consumption, and $\pm 40 \%$ for water consumption. Even the use of detergents and cleaning products may differ between facilities, with an empirically — not tested - good correlation with the use of water. Therefore, a potential variation of $\pm 40 \%$ in the consumption of these products is assumed.

Among the components of module 4 (waste management), which includes plastic from water bottles, disposable tableware, and mixed waste from the kitchen, the latter is the most variable. This happens because the consumption of water bottles and disposable tableware is strictly related to the assumption of one bottle and tableware set per student. These data can be affected mainly by pupil absences (assumed variation lower than 1\%). In contrast, the waste produced in the kitchen is largely related to the dishes that are prepared, and it may change significantly from 1 week to the next. Consequently, a variation of $\pm 25 \%$ in the production of different waste in the kitchens is assumed. 
Fig. 3 Range of variation in the climate change potential of the average meal (represented by the dark central line) for the main sources of variations of each module

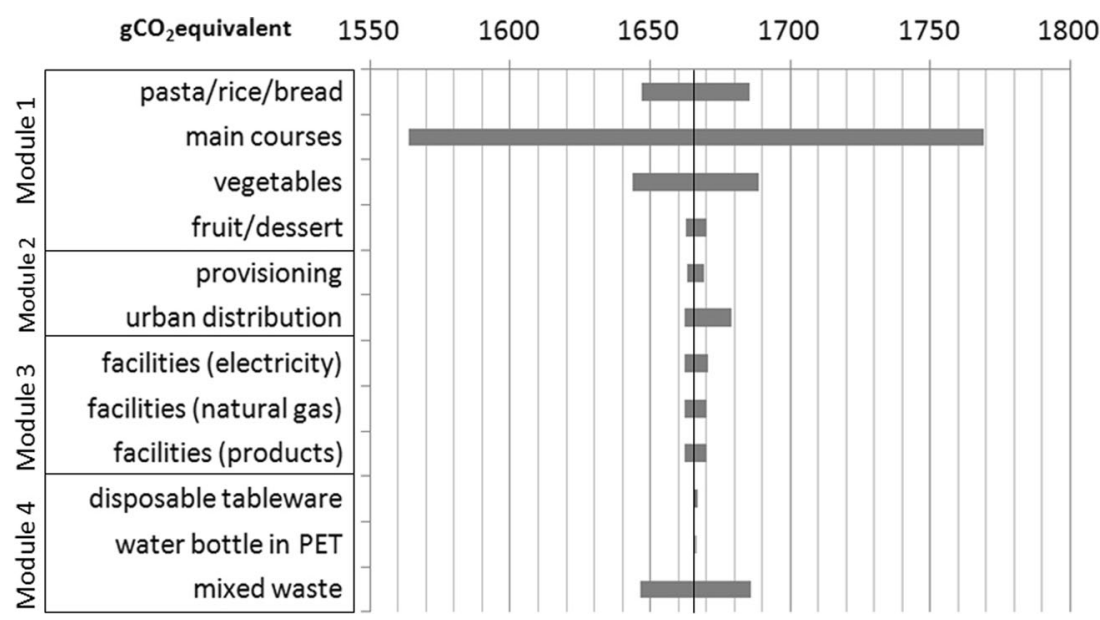

The results of the sensitivity analysis are illustrated in Fig. 3. The overall estimated range of variation of the $\mathrm{CF}$ is $384.7 \mathrm{gCO}_{2} \mathrm{eq}$, with an average meal having a GWP between 1478.2 and $1862.6 \mathrm{gCO}_{2}$ eq. This variability is relatively high (23\% of the estimated CF of the average meal). It should be noted that the majority of this variability $\left(205.3 \mathrm{gCO}_{2} \mathrm{eq}\right)$ can be attributed to the variation in the $\mathrm{CF}$ of the main course, depending on the animal products used (meat, cheese, or eggs). In order to assess the most efficient GPP policies (as discussed in Section 4), this variability must be taken into account.

\section{Reducing the CF using different GPP policies}

\subsection{Potential GPP policies in the school catering service}

Several GPP policies that may be applied to the school catering service were identified, from the literature. One of the most extensive publications on the topic is Neto et al. (2016). Although a sustainability principle always forms the basis of these policies, it is not always possible to calculate an actual $\mathrm{CF}$ reduction. There are several reasons for this-for example, one of the most common GPP policies is the purchase of products with the European Union Ecolabel issued according to 1980/2000 Regulation (EC 2000) and updated by 66/2010 Regulation (EC 2010). To qualify for this label, products must meet strict environmental criteria, but emission reduction cannot be easily estimated for a product that has achieved the label standards. A tentative estimation of the benefits for the $\mathrm{CF}$ of a product obtaining the EU Ecolabel was performed by Baldo et al. (2009). In practical terms, to estimate the benefits of meeting the Ecolabel criteria, it is necessary to perform a full $\mathrm{CF}$ of the specific product, and it is not possible to refer to proxy products or existing databases. Furthermore, because of such specific LCA, an actual CF reduction is not guaranteed; some product groups, e.g. cleaning products, are awarded with the EU Ecolabel for their lower water eutrophication or acidification, which are environmental impacts unrelated to $\mathrm{CF}$.

The GPP policies identified in the literature search are shown in Table 3, categorised according to the module they affect and highlighting those which were considered in this study.

\subsection{Module 1: food production}

In the case study, module 1 'food production' represents by far the phase with the most impact, which is consistent with current knowledge on the topic (Garnett 2011). It is therefore necessary to properly investigate policy options to reduce the impact of this phase. According to several other studies (Caputo et al. 2014; Jungbluth et al. 2016; Smith et al. 2016), two GPP options can be taken by owners of a catering service to reduce impacts from the agricultural phase of consumed foods: (I) the choice of foods from different production practices, in particular the substitution of conventional foods with one produced according to organic production practices, and (II) reducing meat consumption. Another option is to focus on purchasing seasonal produce, but this is primarily a logistical issue that will be discussed in the following section.

In order to compare different production practices, a new set of proxy food products was created. For each proxy food used in the calculation of the baseline scenario, a new LCI was developed according to organic production practices. In practical terms, a new set of organic food proxies was created which consider specific agricultural input reductions as well as average yield reductions. This is described in technical agricultural manuals from the Italian association for organic agriculture $\left(\mathrm{AIAB}^{3}\right)$, organic product specifications from the Italian Ministry of Agriculture (Mipaaf ${ }^{4}$ ), and LCA studies (Notarnicola et al. 2015). Further details about the methods applied for calculating the $\mathrm{CF}$ of the organic counterpart of

\footnotetext{
3 Associazione Italiana per l'Agricoltura Biologica http://www.aiab.it/

${ }^{4}$ Ministero per le politiche agricole, alimentari e forestali https://www. politicheagricole.it
} 
Table 3 List of GPP policies that were included or excluded from the study (and reason), organised by the module they affect

\begin{tabular}{|c|c|c|}
\hline Module affected by the GPP policy & Considered in the study & Not considered in the study (reason) \\
\hline $\begin{array}{l}\text { Module } 1 \\
\text { Food production }\end{array}$ & $\begin{array}{l}\text { - Different production practices for food } \\
\text { - Change food component in the diet }\end{array}$ & $\begin{array}{l}\text { - Organic aquaculture (very limited data available for Italy or Europe) } \\
\text { - Animal welfare and fair trade products (although often considered as } \\
\text { GPP policies, the authors consider these aspects as ethical issues } \\
\text { and out of scope for this analysis) }\end{array}$ \\
\hline $\begin{array}{l}\text { Module } 2 \\
\text { Food logistics }\end{array}$ & $\begin{array}{l}\text { - Local provisioning of food } \\
\text { - Improvements in local distribution of } \\
\text { food }\end{array}$ & $\begin{array}{l}\text { - Buy in-season fruits and vegetables (this approach had already take } \\
\text { place in the baseline scenario of the case study) } \\
\text { - Eco driving course for drivers (no study available for CF reduction } \\
\text { due to driving style) } \\
\text { - Increasing the number of vehicles fuelled by natural gas (it has been } \\
\text { proven to increase the CF even if it lowers other impact categories } \\
\text { such as air quality) (Cerutti et al. 2016). }\end{array}$ \\
\hline $\begin{array}{l}\text { Module } 3 \\
\text { Cooking, storage, and serving }\end{array}$ & $\begin{array}{l}\text { - Adoption of energy efficient appliances } \\
\text { - Electricity from photovoltaic panels } \\
\text { - Certified electricity exclusively from } \\
\text { renewable sources }\end{array}$ & $\begin{array}{l}\text { - Perform an energy efficiency analysis of the facilities (no consistent } \\
\text { data on average savings that can be obtained) } \\
\text { - Use of products with Ecolabel (no data available on the CF reduction } \\
\text { for such products) }\end{array}$ \\
\hline $\begin{array}{l}\text { Module } 4 \\
\text { Waste management }\end{array}$ & $\begin{array}{l}\text { - Washable tableware } \\
\text { - Tableware in Mater-Bi® } \\
\text { - Tap water } \\
\text { - Optimisation of recycling inorganic waste } \\
\text { - Optimisation of composting } \\
\quad \text { organic waste }\end{array}$ & $\begin{array}{l}\text { - Purchase of food with less packaging (inconsistent data available in } \\
\text { LCA studies with less primary and secondary packaging per } \\
\text { food item) }\end{array}$ \\
\hline
\end{tabular}

each conventional food proxy are available in the Electronic Supplementary Material (Table SM02). An organic equivalent was estimated for all proxy foods, except for codfish and tuna, for which data on organic fisheries were not available. In addition to organic certification, certification for sustainable fishing is also a possible GPP option (Smith et al. 2016); however, no standardised data or LCA-based EPDs are available for such products. For the quantification of the potential $\mathrm{CF}$ reduction of this policy, two alternatives to the baseline scenario were considered: the first with $50 \%$ of all food procured from organic farms and the second with $100 \%$ of all food procured from organic farms.

The evaluation of the climate change potential of different diets is not a straightforward process (Pairotti et al. 2015). One of the critical issues is the construction of the alternative menus, which should be balanced in terms of nutrition and health. In this case, the alternative quantity of food required for each food type, in order to balance the absence of meat, was taken directly from the school catering service of the city of Turin. In fact, as well as the standard menu, which includes meat, the municipality offers two alternative menus: (I) one without meat, in which meat is substituted with fish, eggs, cheese, and protein-rich vegetables, and (II) another menu without either meat or fish, which are substituted with eggs, cheese, and protein-rich vegetables. It should be noted that this second alternative is not a fully vegetarian alternative; however, it is one of the best compromises that can be obtained considering catering service possibilities and nutritional needs.

The proportion of each proxy food product in an average meal from the alternative scenarios was calculated exactly as for the standard menu, with reference to the two alternative menus used during the school year 2013/2014 in the secondary class, first grade.

Results of the CF reduction that can be obtained using each GPP policy, and the combination of the two, are presented in Table 4.

The potential reduction of CF per meal by the provision of organic food is up to $189.87 \mathrm{gCO}_{2} \mathrm{eq}$, corresponding to $15 \%$ of module 1 and $11 \%$ of the full meal. This percentage represents a significant reduction considering the low effort that this specific GPP needs. On the contrary, the reduction of animal products is more efficient $(-20 \%$ of the $\mathrm{CF}$ in the menu without meat and $-32 \%$ of the $\mathrm{CF}$ in the menu without meat or fish), but it represents quite a drastic decision to be made by the service and can be adopted only on a voluntary basis by the children and their families. The combined effect of the two options is very relevant as it allows the reduction of the CF up to $42 \%$ of the whole meal. It is interesting to note that the CF of a meal can be reduced by almost one quarter by adopting the intermediate scenario of each of the two GPP policies.

It is important to note that considering just $\mathrm{CF}$ to assess the performance of this module might represent a limitation. In fact, the environmental burdens of the agricultural phase of the food supply chain are also related to eutrophication, acidification, and environmental toxicity (Notarnicola et al. 2015). In particular, a proper assessment of the ecotoxity linked to pesticide use in the food supply chain might be crucial when comparing conventional and organic food products (Nordborg et al. 2017). 
Table 4 Breakdown of potential $\mathrm{CF}$ reduction according to the combination of different scenarios with conventional, $50 \%$ organic, and $100 \%$ organic (on vertical axes) and standard menu, a menu without meat, and a menu without meat and fish (on horizontal axes). Results are expressed in $\mathrm{gCO}_{2}$ eq and percentage of reduction in comparison with the baseline scenario

\begin{tabular}{|c|c|c|c|c|c|c|c|}
\hline & & \multicolumn{2}{|c|}{ Standard menu } & \multicolumn{2}{|c|}{ No meat menu } & \multicolumn{2}{|c|}{$\begin{array}{l}\text { No meat, no fish } \\
\text { menu }\end{array}$} \\
\hline & & $\mathrm{gCO}_{2} \mathrm{eq}$ & $\begin{array}{l}\% \\
\text { reduction }\end{array}$ & $\mathrm{gCO}_{2} \mathrm{eq}$ & $\begin{array}{l}\% \\
\text { reduction }\end{array}$ & $\mathrm{gCO}_{2} \mathrm{eq}$ & $\begin{array}{l}\% \\
\text { reduction }\end{array}$ \\
\hline \multirow[t]{6}{*}{ Conventional } & Pasta/rice/bread & 129.68 & - & 129.68 & $0 \%$ & 129.68 & $0 \%$ \\
\hline & Main courses & 1026.72 & - & 693.35 & $-32 \%$ & 468.80 & $-54 \%$ \\
\hline & Vegetables & 112.20 & - & 112.20 & $0 \%$ & 134.64 & $-20 \%$ \\
\hline & Fruit/dessert & 24.57 & - & 24.57 & $0 \%$ & 24.57 & $0 \%$ \\
\hline & $\begin{array}{l}\text { Module 1- } \\
\quad \text { subtotal }\end{array}$ & 1293.17 & - & 959.80 & $-26 \%$ & 757.69 & $-41 \%$ \\
\hline & Scenario-total & 1666.26 & - & 1332.88 & $-20 \%$ & 1130.77 & $-32 \%$ \\
\hline \multirow[t]{6}{*}{$50 \%$ organic } & Pasta/rice/bread & 116.71 & $-10 \%$ & 116.71 & $-10 \%$ & 116.71 & $-10 \%$ \\
\hline & Main courses & 981.04 & $-4 \%$ & 670.82 & $-35 \%$ & 438.33 & $-57 \%$ \\
\hline & Vegetables & 80.22 & $-29 \%$ & 80.22 & $-29 \%$ & 96.27 & $-14 \%$ \\
\hline & Fruit/dessert & 20.27 & $-18 \%$ & 20.27 & $-18 \%$ & 20.27 & $-18 \%$ \\
\hline & $\begin{array}{l}\text { Module } 1- \\
\text { subtotal }\end{array}$ & 1198.24 & $-7 \%$ & 888.02 & $-31 \%$ & 671.58 & $-48 \%$ \\
\hline & Scenario - total & 1571.32 & $-6 \%$ & 1261.10 & $-24 \%$ & 1044.66 & $-37 \%$ \\
\hline \multirow{6}{*}{$\begin{array}{l}100 \% \\
\text { organic }\end{array}$} & Pasta/rice/bread & 103.75 & $-20 \%$ & 103.74 & $-20 \%$ & 103.74 & $-20 \%$ \\
\hline & Main courses & 935.35 & $-9 \%$ & 648.28 & $-37 \%$ & 407.85 & $-60 \%$ \\
\hline & Vegetables & 48.25 & $-57 \%$ & 48.24 & $-57 \%$ & 57.89 & $-48 \%$ \\
\hline & Fruit/dessert & 15.97 & $-35 \%$ & 15.96 & $-35 \%$ & 15.96 & $-35 \%$ \\
\hline & $\begin{array}{l}\text { Module } 1- \\
\text { subtotal }\end{array}$ & 1103.31 & $-15 \%$ & 816.24 & $-37 \%$ & 585.46 & $-55 \%$ \\
\hline & Scenario-total & 1476.39 & $-11 \%$ & 1189.33 & $-29 \%$ & 958.55 & $-42 \%$ \\
\hline
\end{tabular}

\subsection{Module 2: food logistics}

The relevance of the impact of the transport of food from production to the consumption site is extensively debated in the literature. For some authors (Roy et al. 2009; Smith et al. 2016), it is considered one of the most important factors to be controlled in order to achieve sustainable food consumption. For other authors the impact of long distances is less relevant than storage (Mila i Canals et al. 2007) or the efficiency of agricultural practices (Jungbluth et al. 2016).

GPP options for reducing food transport may be focused either on the large transport distances from the production site to the market or the peri-urban hubs or the shorter distances from the market or peri-urban hubs to consumption sites.

To estimate the CF reduction in the provisioning phase due to GPP policies, a geographical origin requirement was considered. For example, one scenario could be to restrict the place of origin for all major foods to the local region. Excluding some fruits, a few vegetables and a few ingredients (such as olive oil), a large majority of the agricultural products could theoretically be produced in the region. Therefore, the provisioning route of each proxy food item used in the baseline scenario (according to data collected from retailers) was modified, assuming that the provision of food will be shifted from the international market to the regional market. The theoretical potential of the regional market to support the quantity of food requested was verified through interviews with retailers. Results of this analysis are in line with the results for three fruit and two vegetable supply chains as calculated in a separate study (Cerutti et al. 2016). The adoption of requirements for regional sourcing of the proxy food items used in the baseline scenario led to an overall saving of $3.35 \mathrm{gCO}_{2}$ eq per average meal. This amount corresponds to $27 \%$ of the $\mathrm{CF}$ of the provisioning in the baseline scenario (12.21 $\left.\mathrm{gCO}_{2} \mathrm{eq}\right)$. This result shows that imposing a limit on the geographical origin of food can be very efficient in reducing the impact of transport; however, the achieved $\mathrm{CF}$ reduction represents $5.85 \%$ of the module and just $0.20 \%$ of the CF of the full catering service.

GPP policies on logistics could also concern urban distribution. In this case, two options for improvements were considered, both focusing on the optimisation of transport routes. The first option is based on the reduction of distances that took place in the catering service because of a reorganisation of the distribution routes (Cerutti et al. 2016). The second option was calculated according to the hypothesis of establishing new cooking centres in the city. The number of cooking centres was increased from five to ten, one for each district of the city, to simulate a more diffuse delivery of the food. The reduction in distance for a single final delivery is shown in Fig. 4. 


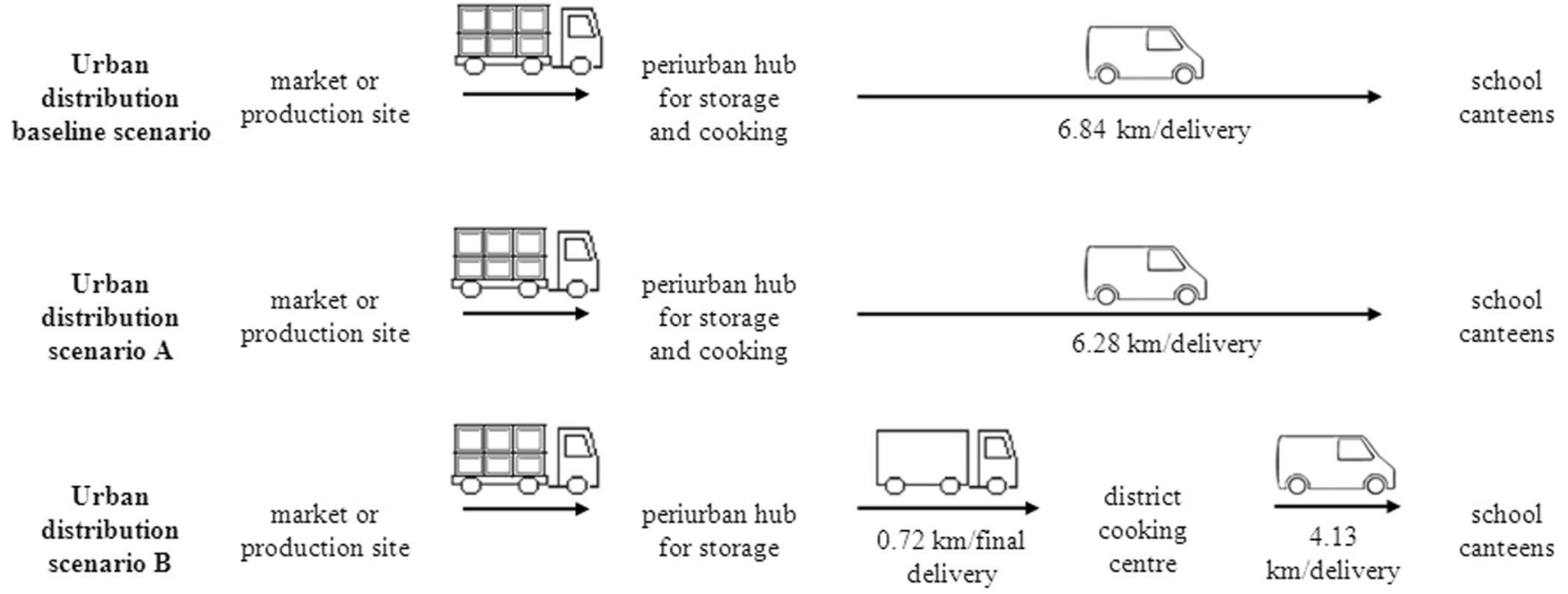

Fig. 4 Baseline scenario and optimised scenarios for the urban distribution within module 2

In comparison to the baseline scenario, the first option to reduce the distances leads to a reduction of $8 \% \mathrm{~km}$ per delivery. Considering the same pool of cars from the preceding year, this reduction in the distances corresponds to $5.83 \%$ of the CF of the module, equivalent to $0.20 \%$ of the total emissions of the service.

The second alternative scenario, although completely theoretical, may lead to a higher reduction of the distances: $29.38 \% \mathrm{~km}$ per delivery, which represents $16.54 \%$ of the CF the module, and $0.54 \%$ of the total emissions of the service. It should be noted that such a result is based on the theoretical distance that would be travelled by transport vans, without considering the feasibility of such a solution in the urban context-for example, whether suitable buildings and facilities are available.

As the GPPs described above influence different aspects of the transportation of food, it could be possible to apply them both in a merged scenario, which represents a best-case scenario for the module. Considering both GPP options, the best-case scenario achieves a reduction of $27.25 \%$ of the CF of the module, equivalent to $0.94 \%$ of the total $\mathrm{CF}$ of the catering service.

According to previous studies (Alvarez et al. 2012; Lopez et al. 2009), changing the energy vector, e.g. from petrol to natural gas, was not considered as a suitable option for reducing the climate change potential of the catering service. This was because natural gas has proven to be very effective in increasing the air quality, but it may have a negative performance in the reduction of GHG emissions because of the lower efficiency of the vehicles (Lopez et al. 2009). Furthermore, the use of electric vehicles was not considered, since this option was not considered to be viable by the municipality, due to the absence of facilities for recharging the vehicles.

The attention to just the CF in this module has the limitation of not addressing local effects due to the lowering of fuel consumption, such as the improvement of air quality and the reduction of photochemical smog. This module could also be studied from the perspective of human health-oriented indicators (such as DALy - disability-adjusted life year) as the air quality in highly populated cities strongly affects life expectancy and quality (WHO 2013).

\subsection{Module 3: cooking, storage, and service}

Food preparation and service represents a stage of the catering service in which technical aspects may play a key role in lowering the $\mathrm{CF}$ because the emissions in this stage are strongly related to energy consumption and products used. The biggest source of GHG emissions at this stage is electricity consumption in the kitchens and schools ( $6.27 \%$ of the CF of the full service); the next highest source is the consumption of natural gas in kitchens (1.16\% of the CF of the full service). A small part is due to the life cycle of equipment and facilities $(0.56 \%$ of the $\mathrm{CF}$ of the full service). Consequently, the most relevant options for $\mathrm{CF}$ reduction in this module should focus on electricity consumption, including electricity savings, e.g. adopting energy efficient equipment and practices and by changing the provision of electricity by moving to a greener source of electricity.

According to Bertoldi and Atanasiu (2009), moving from a low energy class appliance to one belonging to the top classes could allow very high savings, up to $80 \%$. However, these savings are largely dependent on the type of appliance. Moreover, a large share of appliances used today already belongs to high classes according, for example, to the EU Energy Labelling Directive (2010/30/EU). For example, De Almeida et al. (2011) estimated that $90 \%$ of domestic appliances sold in the EU are already in class ' $A$ ' or higher. Ardente and Mathieux (2014) estimated that, referring to the current European energy labelling of washing machines, the substitution of a product of energy class ' $A$ ' to one of class 'A+' implies a reduction of $12 \%$ of the energy consumption during 
use, while substituting it with a washing machine of class 'A++' would allow a reduction of the energy consumption of about $22 \%$. More recently, Bobba et al. (2016) estimated that improving the energy efficiency of a vacuum cleaner by a $15 \%$ is equivalent to moving up one energy efficiency class. Current European energy labelling focuses more on household appliances, while energy labelling schemes for professional appliances are generally missing. Nevertheless, it is reasonable to assume that the increase of $15 \%$ in energy efficiency for each energy class can also be applied to professional appliances. In order to estimate the electricity savings due to the use of more efficient appliances, two scenarios were assumed: (I) minor savings, considering a $15 \%$ energy efficiency improvement (an advancement of one energy class), leading to a reduction of $15.67 \mathrm{gCO}_{2}$ eq per average meal, and corresponding to $12 \%$ of the $\mathrm{CF}$ of the module and $1 \%$ of the $\mathrm{CF}$ of the full service, and (II) major savings, considering a 30\% energy efficiency improvement (an advancement of two energy classes), leading to a reduction of $31.34 \mathrm{gCO}_{2} \mathrm{eq}$ per average meal, and corresponding to $24 \%$ of the $\mathrm{CF}$ of the module and $2 \%$ of the $\mathrm{CF}$ of the full service.

The second option for reducing the $\mathrm{CF}$ of the cooking and serving stage is to lower the GHG emissions from electricity consumption. This can be done either by installing renewable energy sources to produce electricity (e.g. photovoltaic panels) in the facilities or by purchasing greener electricity from suppliers. For the first case, the emission factor for electricity production in ECOINVENT 2.0 has been used $\left(0.068 \mathrm{kgCO}_{2} \mathrm{eq} /\right.$ $\mathrm{kWh}$ for electricity generated by photovoltaic panels) instead of the Italian grid mix supply (data from ELCD). This shift leads to an absolute saving of $80.21 \mathrm{gCO}_{2}$ eq per average meal, corresponding to $60 \%$ of the $\mathrm{CF}$ of the module and $5 \%$ of the $\mathrm{CF}$ of the full catering service.

To quantify the savings due to the purchasing of certified electricity from renewable sources, an average production mix of renewable sources was defined as $20 \%$ photovoltaic, $35 \%$ hydropower, $35 \%$ wind power, and $10 \%$ from biomass, per the proportions of these technologies in the electricity mix in Italy in 2015. The estimated emission factor of this renewable energy mix is $0.023 \mathrm{kgCO}_{2} \mathrm{eq} / \mathrm{kWh}$, based on the emissions of different energy sources available in the database ECOINVENT 2.0. This shift leads to an absolute savings of $100.32 \mathrm{gCO}_{2}$ eq per average meal, corresponding to $75 \%$ of the $\mathrm{CF}$ of the module and $6 \%$ of the $\mathrm{CF}$ of the full service.

Also, in this module, focusing on the CF alone could result in a limited assessment of the non-climate environmental impacts, as most of the chemical products used in kitchens and school canteens affect water pollution and eutrophication.

\subsection{Module 4: waste management}

Decreasing environmental impacts from waste is seen as a priority in most of the catering services. There are two main components: reducing the source of waste (food and materials) by different consumption behaviours and different materials or improving the waste management systems. Caputo et al. (2014) suggest focusing on different systems of waste management. On the contrary, Smith et al. (2016) and Jungbluth et al. (2016) discussed the importance of reducing waste from the packaging of meals, inedible parts of food, and leftovers.

The first GPP that can be tested relates to the material of the tableware used in the catering service. Three options are available: disposable tableware made from petroleum-based plastic, disposable tableware made from biomaterials, and washable tableware. The first option has been considered to calculate the baseline scenario, while the other two options were considered as possible improvements. For both options, the full life cycle of the same set of components considered in the average meal in the baseline scenario was calculated. For the scenario in which bio-based tableware is used, all tableware components (three plates, one cup, and cutlery) were considered to made from Mater-Bi ${ }^{\circledR}$, but following results of a market survey, primary and secondary packaging were assumed to be made of the same materials as in the standard scenario. Emission factors for the life cycle of components in Mater$\mathrm{Bi}{ }^{\circledR}$ were taken from Razza et al. (2009). In this scenario, the $\mathrm{CF}$ reduction is $14.72 \mathrm{gCO}_{2}$ eq per average meal, corresponding to $8.06 \%$ of the $\mathrm{CF}$ of the module and $0.88 \%$ of the $\mathrm{CF}$ of the full service (Table 4).

Testing the option of using washable tableware is more complex. Plates, cups, and cutlery used in schools cannot be made from materials that can harm children; therefore, no metal or ceramics can be used. The material considered as a reference in this study was melamine resin, using emission factors from the ECOINVENT version 3 database. However, the adoption of this option is not just a matter of materials - it would require the additional service of washing and the replacement of broken tableware. This would require extra consumption of water and electricity and the need for additional space for the appliances in the schools or in the kitchen. Therefore, the application of this option might be difficult in practice because of limited available space.

For the assessment of the CF of this scenario, two subscenarios were considered: (I) dedicated transport of dishes and (II) dishes are moved together with food back and forth to the peri-urban hubs. It should be noted that the reduction of waste from the adoption of washable tableware brings an increase in water and electricity consumption that are assessed in module 3 and not in module 4 . Thus, in both sub-scenarios I and II, the GHG emission saving in module 4 is $50 \mathrm{gCO}_{2} \mathrm{eq}$ for the average meal but with an increase of $38 \mathrm{gCO}_{2} \mathrm{eq}$ in modules 2 and 3 for scenario I and an increase of $17 \mathrm{gCO}_{2} \mathrm{eq}$ in modules 3 for scenario II (see Table 5 for details). As an overall result, the washable tableware moved together with the food allows for a CF reduction of almost $2 \%$ of the full service. 
Table 5 Climate change potential reduction of different scenarios. The baseline scenario (disposable polyethylene tableware) is compared to the use of tableware made from Mater-Bi ${ }^{\circledR}$ and washable tableware

\begin{tabular}{|c|c|c|c|c|c|c|c|}
\hline & \multirow{2}{*}{$\begin{array}{l}\text { Baseline scenario } \\
\mathrm{gCO}_{2} \mathrm{eq}\end{array}$} & \multicolumn{2}{|c|}{ Mater-Bi ${ }^{\circledR}$ tableware } & \multicolumn{2}{|c|}{$\begin{array}{l}\text { Washable tableware (I) with } \\
\text { dedicated transport }\end{array}$} & \multicolumn{2}{|c|}{$\begin{array}{l}\text { Washable tableware (II) without } \\
\text { dedicated transport }\end{array}$} \\
\hline & & $\mathrm{gCO}_{2} \mathrm{eq}$ & $\%$ reduction & $\mathrm{gCO}_{2} \mathrm{eq}$ & $\%$ reduction & $\mathrm{gCO}_{2} \mathrm{eq}$ & $\%$ reduction \\
\hline Module 2 & 57.30 & 57.30 & - & 78.17 & $+36.42 \%$ & 57.30 & - \\
\hline Module 3 & 133.17 & 133.17 & - & 150.35 & $+12.90 \%$ & 150.35 & $+12.90 \%$ \\
\hline Waste from tableware & 63.08 & 48.35 & $-23.34 \%$ & 12.99 & $-79.40 \%$ & 12.99 & $-79.40 \%$ \\
\hline Other waste & 119.53 & 119.53 & - & 119.53 & - & 119.53 & - \\
\hline Module 4 subtotal & 182.61 & 167.89 & $-8.06 \%$ & 132.53 & $-27.43 \%$ & 132.53 & $-27.43 \%$ \\
\hline Scenario-total & 1666.26 & 1651.53 & $-0.88 \%$ & 1654.23 & $-0.72 \%$ & 1633.36 & $-1.97 \%$ \\
\hline
\end{tabular}

Regarding other waste that is generated by the catering service, a special case is presented by plastics from bottled water. A significant share $(22 \%)$ of the CF of the module is due exclusively to the life cycle of such packaging. In this case, a very simple GPP policy recommendation can be made: the substitution of bottled water with tap water. For the assessment of the CF reduction of this option, the full life cycle of tap water was considered, including the production of water carafes (with a substitution rate of $5 \%$ due to damage, based upon interviews with school catering operators), the washing of carafes (in terms of electricity consumption and cleaning products), and GHG emissions due to the water from the aqueduct. This latter aspect was quantified using the EPD of the tap water of the municipality of Lizzano in Belvedere (EPD 2008) as a proxy for the city of Turin. It is estimated that this GPP option would produce a reduction of $41.03 \mathrm{gCO}_{2}$ eq per meal in module $4(22.47 \%$ of the $\mathrm{CF}$ of the module) and an increase of $2.09 \mathrm{gCO}_{2}$ eq per meal in module 3 ( $1.57 \%$ of the $\mathrm{CF}$ of the module). The net reduction resulted in $38.94 \mathrm{gCO}_{2}$ eq per meal, which corresponds to $2.34 \%$ of the $\mathrm{CF}$ of the full catering service.

Fig. 5 Breakdown of the waste (mass expressed in grams and percentage) generated in the preparation and serving of an average meal
Another option for CF reduction is related to the enforcement of good practices for waste management. In the baseline scenario, the mass of waste produced for an average meal during the processing and the serving phases is $61 \mathrm{~g}$ (excluding plastic bottles and tableware, which are assessed separately) of which $71 \%$ is made of organic material (see the breakdown of waste in Fig. 5). The food processed but not served represents a significant share of the waste generated. This accounts for $4.56 \%$ of the total amount of food processed. This value is significantly lower than identified by Falasconi et al. (2015), who estimated that $15.31 \%$ of the overall processed food was not served in a sample of six schools located in the municipality of Verona (Italy). This lower percentage can be partially explained by the fact that giving the students several menus to choose from increases the possibility of meeting food preferences and decreasing the chance of wasted food. Also, the amount of leftover food is low (almost $2 \%$ of the food served) because of campaigns already performed by the municipality to reduce waste (see Section 2.2-modelling module 4).

In the baseline scenario, it was assumed that waste is disposed of in landfills, adopting an average emission factor of $1.287 \mathrm{gCO}_{2} \mathrm{eq} / \mathrm{g}$ of waste (Lou and Nair 2009). This emission

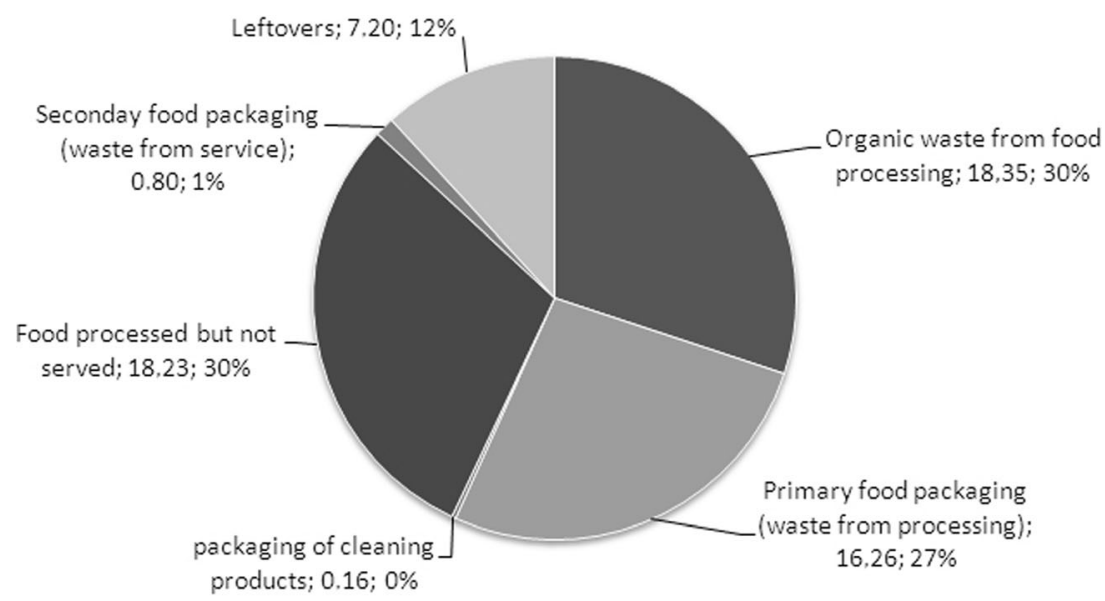


value, although quite generic, is considered to be a suitable reference for the 'option-zero' scenario (e.g. without considering energy recovering from biogas), and it is also considered as a representative of the Italian context (Capaccioni et al. 2011). It is important to note that impacts from landfilling as well as other waste management options might not be properly captured by CF (Ménard et al. 2004).

According to the most common modelling practices of production systems (e.g. Baumann and Tillman 2004), there are two ways of allocating the impact of composting or recycling: (I) to the systems where primary products are used or (II) to the production system in which recycled materials are inputs but including also credits due to the avoided production of new material. As an example of the second approach, if the compost produced by the treatment of the organic fraction is used in agriculture in place of fertilisers or soil conditioners, the environmental impacts of the waste treatment as well as the credits of avoided materials should be allocated to cultivation using the compost. Consequently, from the point of view of the system that produces the waste, if the composting or recycling processes properly take place, the net environmental burden of such waste is null. Therefore in this study, the focus is on the system that produces waste (and not on the one that uses composted/recycled products), neither the environmental impact of composting/recycling nor the environmental credit of using composted/recycled products is considered. To estimate the effects of potential options for waste management on the $\mathrm{CF}$, a shift to different shares of food waste composting and other waste recycling was assumed, as illustrated in Table 6. The share of composting and recycling used are just examples; in fact, reaching $100 \%$ share in both processes is unlikely because certain types of food packaging are not recyclable and because sometimes food waste from schools is not properly sorted. The highest reduction that is achievable, focusing exclusively on the recycling of inorganic waste or on the composting of food waste, is around $3 \%$ of the CF of the full service. The combined effect of both targets would allow a reduction of around $6 \%$ of the $\mathrm{CF}$ of the full service.

The concurrent adoption of the three GPP requirements described in this section, in their optimum scenarios (just tap water, washable tableware, $80 \%$ composting of organic waste and $90 \%$ recycling of inorganic waste) leads to a net reduction in the $\mathrm{CF}$ of the module of $159.55 \mathrm{gCO}_{2}$ eq per meal $(87 \%$ of module 4), including the increase of $19.27 \mathrm{gCO}_{2}$ eq per meal (14\% of module 3 ) due to the increased consumption of electricity, water, and cleaning products, accounted for in module 3.

\section{Discussion}

Some GPP policies are very efficient in the module they affect, but in the overall assessment, the reduction they produce is quite limited. Therefore, the summary presented in Table 7 to provide an overview of the CF reduction of the various GPP policies assessed is elaborated upon here. Together with the calculation of absolute and relative CF reduction, Table 7

Table 6 Breakdown of climate change potential reduction according to the combination of different scenarios, with the composting of organic waste at 0,50 , and $90 \%$ and the recycling of inorganic waste at 0,40 , and $80 \%$. Results are expressed in $\mathrm{gCO}_{2}$ eq and a percentage reduction in comparison with the baseline scenario

\begin{tabular}{|c|c|c|c|c|c|c|c|}
\hline & & \multicolumn{2}{|c|}{ Organic composting $0 \%$ (baseline scenario) } & \multicolumn{2}{|c|}{ Organic composting $40 \%$} & \multicolumn{2}{|c|}{ Organic composting $80 \%$} \\
\hline & & $\mathrm{gCO}_{2} \mathrm{eq}$ & $\%$ reduction & $\mathrm{gCO}_{2} \mathrm{eq}$ & $\%$ reduction & $\mathrm{gCO}_{2} \mathrm{eq}$ & $\%$ reduction \\
\hline \multirow{5}{*}{$\begin{array}{l}\text { Inorganic recycling } 0 \% \\
\text { (baseline scenario) }\end{array}$} & Waste not recyclable & 63.08 & - & 63.08 & - & 63.08 & - \\
\hline & Organic waste & 56.35 & - & 28.17 & $-50.00 \%$ & 5.63 & $-90.00 \%$ \\
\hline & Inorganic waste & 63.19 & - & 63.19 & $0.00 \%$ & 63.19 & $0.00 \%$ \\
\hline & Module 4-subtotal & 182.61 & - & 154.44 & $-15.43 \%$ & 131.90 & $-27.77 \%$ \\
\hline & Scenario total & 1666.26 & - & 1638.08 & $-1.69 \%$ & 1615.55 & $-3.04 \%$ \\
\hline \multirow[t]{5}{*}{ Inorganic recycling $40 \%$} & Waste not recyclable & 63.08 & - & 63.08 & - & 63.08 & - \\
\hline & Organic waste & 56.35 & $0.00 \%$ & 28.17 & $-50.00 \%$ & 5.63 & $-90.00 \%$ \\
\hline & Inorganic waste & 37.91 & $-40.00 \%$ & 37.91 & $-40.00 \%$ & 37.91 & $-40.00 \%$ \\
\hline & Module 4-subtotal & 157.34 & $-13.84 \%$ & 129.16 & $-29.27 \%$ & 106.63 & $-41.61 \%$ \\
\hline & Scenario total & 1640.98 & $-1.52 \%$ & 1612.81 & $-3.21 \%$ & 1590.27 & $-4.56 \%$ \\
\hline \multirow[t]{5}{*}{ Inorganic recycling $80 \%$} & Waste not recyclable & 63.08 & - & 63.08 & - & 63.08 & - \\
\hline & Organic waste & 56.35 & $0.00 \%$ & 28.17 & $-50.00 \%$ & 5.63 & $-90.00 \%$ \\
\hline & Inorganic waste & 12.64 & $-80.00 \%$ & 12.64 & $-80.00 \%$ & 12.64 & $-80.00 \%$ \\
\hline & Module 4-subtotal & 132.06 & $-27.68 \%$ & 103.89 & $-43.11 \%$ & 81.35 & $-55.45 \%$ \\
\hline & Scenario total & 1615.71 & $-3.03 \%$ & 1587.53 & $-4.72 \%$ & 1565.00 & $-6.08 \%$ \\
\hline
\end{tabular}


Table 7 Summary of the potential CF reduction of the 11 GPP options assessed in this paper, in their specific best-case scenarios, compared to the baseline scenario. Aspects highlighted are the absolute reduction of CF per meal and the relative reduction of CF in the module that is affected by the GPP policy and in the full catering service

\begin{tabular}{|c|c|c|c|c|c|}
\hline Module & GPP policy & $\begin{array}{l}\text { Absolute reduction } \\
\text { per meal }\left(\mathrm{gCO}_{2}{ }^{1} \mathrm{eq}\right)\end{array}$ & $\begin{array}{l}\text { Relative reduction in } \\
\text { the module ( } \% \\
\text { reduction) }\end{array}$ & $\begin{array}{l}\text { Relative reduction in } \\
\text { the full service (\% } \\
\text { reduction) }\end{array}$ & $\begin{array}{l}\text { Difficulties in the application } \\
\text { of the GPP policy }\end{array}$ \\
\hline \multirow[t]{2}{*}{$\begin{array}{l}\text { Module } 1 \\
\text { Food production }\end{array}$} & $\begin{array}{l}\text { Different production } \\
\text { practices for food }\end{array}$ & -189.87 & $-15 \%$ & $-11.39 \%$ & $\begin{array}{l}\text { Medium (difficulties related to } \\
\text { the certification schemes) }\end{array}$ \\
\hline & $\begin{array}{l}\text { Change food component } \\
\text { in the diet }\end{array}$ & -535.48 & $-41 \%$ & $-32.14 \%$ & $\begin{array}{l}\text { High (difficulties related to social, } \\
\text { economic and nutritional issues) }\end{array}$ \\
\hline \multirow[t]{2}{*}{$\begin{array}{l}\text { Module } 2 \\
\text { Food transport }\end{array}$} & Local provisioning of food & -3.35 & $-6 \%$ & $-0.20 \%$ & $\begin{array}{l}\text { Medium (difficulties in providing } \\
\text { enough local food of the requested } \\
\text { quality) }\end{array}$ \\
\hline & $\begin{array}{l}\text { Improvements in local } \\
\text { distribution of food }\end{array}$ & -12.26 & $-16 \%$ & $-0.74 \%$ & $\begin{array}{l}\text { High (difficulties in the urban } \\
\text { dimensions and need for facilities) }\end{array}$ \\
\hline \multirow{3}{*}{$\begin{array}{l}\text { Module } 3 \\
\text { Cooking, storage, } \\
\text { and serving }\end{array}$} & $\begin{array}{l}\text { Adoption of energy efficient } \\
\text { appliances }\end{array}$ & -31.34 & $-24 \%$ & $-1.88 \%$ & $\begin{array}{l}\text { Medium (difficulties related to the } \\
\text { labelling of professional appliances) }\end{array}$ \\
\hline & $\begin{array}{l}\text { Electricity from } \\
\text { photovoltaic panels }\end{array}$ & -80.21 & $-60 \%$ & $-4.81 \%$ & $\begin{array}{l}\text { High (difficulties related to economic } \\
\text { and logistic issues) }\end{array}$ \\
\hline & $\begin{array}{l}\text { Certified electricity exclusively } \\
\text { from renewable sources }\end{array}$ & -100.32 & $-75 \%$ & $-6.02 \%$ & $\begin{array}{l}\text { Medium (difficulties related to } \\
\text { economic issues) }\end{array}$ \\
\hline \multirow[t]{5}{*}{$\begin{array}{l}\text { Module } 4 \\
\text { Waste } \\
\quad \text { management }\end{array}$} & Washable tableware & $-50(+17$ in $\mathrm{M} 3)$ & $-27 \%(+12 \%$ in $\mathrm{M} 3)$ & $-1.97 \%$ & $\begin{array}{l}\text { Medium (difficulties related to } \\
\text { costs and to the creation of } \\
\text { facilities for cleaning) }\end{array}$ \\
\hline & Mater-Bi ${ }^{\circledR}$ tableware & -15 & $-8 \%$ & $-0.88 \%$ & Low (no significant difficulties revealed) \\
\hline & Tap water & $-41(+2$ in $M 3)$ & $-22 \%(+1 \%$ in $\mathrm{M} 3)$ & $-2.34 \%$ & Low (no significant difficulties revealed) \\
\hline & $\begin{array}{l}\text { Optimisation }(80 \%) \text { of the } \\
\text { recycling of inorganic waste }\end{array}$ & -50 & $-28 \%$ & $-3.03 \%$ & $\begin{array}{l}\text { Low (difficulties can be overcome } \\
\text { by the training of operators) }\end{array}$ \\
\hline & $\begin{array}{l}\text { Optimisation }(90 \%) \text { of the } \\
\text { composting of organic waste }\end{array}$ & -50 & $-27 \%$ & $-3.04 \%$ & $\begin{array}{l}\text { Low (difficulties can be overcome } \\
\text { by the training of operators) }\end{array}$ \\
\hline
\end{tabular}

qualitatively discusses the potential difficulties that could arise from the policy enforcement. These difficulties are based on the expert judgments collected by the steering committee during the INNOCAT project meetings.

The GPP policies that lead to the highest potential CF reduction are also those that are more difficult to apply. In particular, moving to a vegetarian diet will potentially reduce the overall $\mathrm{CF}$ by $32 \%$. This effect is due to the high relative impacts of module 1, and it is in line with several studies on the CF of livestock (Garnett 2009; Steinfeld et al. 2006). Nevertheless, although a decrease in meat consumption is supported by the World Health Organisation (WHO 2015), a complete shift is very controversial from a nutritional point of view. Furthermore, environmental and behavioural aspects are strictly bounded, requiring a dialogue among the different stakeholders involved. Therefore, the application of this option requires the development of a more comprehensive method for the assessment of the sustainability of the food system in schools (Rojas et al. 2011), which should also address behavioural and nutritional aspects.

The relative impact of food production on the $\mathrm{CF}$ of the catering service is also highlighted by the significant CF reduction that can potentially be achieved by the shift to the exclusive use of organic food (around $11 \%$ of the CF of the catering service). One of the most relevant limitations of this GPP policy occurs when the provisioning of organic products must take place in the local area, because of the limited availability of such products in the regional context. When considering GPP options focused on food production (e.g. focusing on the production of organic food or reducing animal products), it is important to keep in mind the high variability of the $\mathrm{CF}$ in this phase. The variability of the CF of the main courses assessed in Section 3.3 (205.3 $\mathrm{gCO}_{2}$ eq) is higher than the $\mathrm{CF}$ reduction produced by the purchasing of organic products $\left(189.87 \mathrm{gCO}_{2} \mathrm{eq}\right)$, and it is almost half of the $\mathrm{CF}$ reduction for the scenario without animal products $\left(535.48 \mathrm{gCO}_{2} \mathrm{eq}\right)$. This aspect leads to the consideration that, more than a policy focused on certain production practices, it may be more effective to adopt a policy that encourages the purchasing of foods with a lower CF based, for example, on environmental product declarations or certifications.

A lower (but still relevant) share of CF reduction of the service can be achieved by focusing on the electricity consumed (module 3 ). Since the energy sources used to produce electricity strongly affect the GHG emissions into the atmosphere, these are relevant for the CF of the service. It is interesting to note that the adoption of energy efficient appliances (although difficult because of the lack of energy efficient labelling of professional appliances) can be coupled with the shift to a different power grid mix for electricity, leading to an overall CF potential reduction to around $7.8 \%$. 
The third major area of reduction is related to waste management. The first aspect is that all considered GPP policies that affect this part of the service can be applied with relatively low effort from the caterer, but summarising all of them, they can potentially lead to a reduction of around $10 \%$ of the CF of the full service. This reduction is already quite significant, but another technical aspect related to the choice of the environmental indicator must also be considered. The $\mathrm{CF}$ might not be the best indicator to fully include the environmental impact from waste management (Allacker et al. 2014). As proven for other product groups and services, the recycling of waste can be relevant for impacts such as consumption of resources (Latunussa et al. 2016). The same uncertainty affects the quantification of the $\mathrm{CF}$ reduction of bioplastics. In fact, the most relevant environmental benefits of using bio-based materials instead of petrol-based plastics are not related to $\mathrm{CF}$ reduction but to other ecological aspects which are not always properly addressed by LCA, such as the effect of plastic pollution on biodiversity and ecosystem health (Razza and Cerutti 2017).

Because of the relatively low impact of the logistical stages on the $\mathrm{CF}$ of the full catering service (3.4\%), the $\mathrm{CF}$ reduction that can be achieved by GPP policies that target this module is quite limited. This result is partially in contrast with what was estimated in a previous study by Cerutti et al. (2016) in which the CF reduction due to GPP policies targeting the logistical phases was higher. However, this difference should be related to the different system boundaries considered. Cerutti et al. (2016) focused exclusively on the supply chain (including production, distribution, and urban transportation) of five example foods, while excluding all other stages of food management in the kitchens and schools.

Shifting from an international to a regional sourcing of food allows a reduction of $22 \%$ of the GHG emissions of the transport (see Section 4.3). However, when the full catering service is considered, this option produces a reduction of less than $1 \%$ of the overall CF. This applies as well to the policy on the rationalisation of urban distribution. This policy potentially reduces $23 \%$ of the GHG emissions of the urban distribution, which corresponds to less than $1 \%$ of the $\mathrm{CF}$ of the full catering service. It is very important to consider this result in order to properly assess and prioritise this GPP policy in comparison to others.

Furthermore, it is interesting to consider the effects of adopting two or more GPP policies at the same time. However, in some cases, the considered GPP policies were self-excluding (i.e. the use of either washable tableware or tableware produced in Mater-Bi®; the purchasing of certified electrify from the power grid or the production of electricity from photovoltaic panels). Moreover, the CF reduction produced by a combination of all the possible options is very high, although some combinations are not applicable or relevant. As an example, it is possible to consider the simultaneous adoption of GPP polices with the same level of difficulty, as suggested in
Table 7. By applying only the policies with a low difficulty, a net reduction of $154 \mathrm{gCO} 2 \mathrm{eq} / \mathrm{meal}$, which corresponds to a $\mathrm{CF}$ reduction of $9.24 \%$, could be achieved. Furthermore, considering all policies with low and medium difficulties (including the best option for the self-excluding cases), a net reduction of $524 \mathrm{gCO} 2 \mathrm{eq} / \mathrm{meal}$, which corresponds to a $\mathrm{CF}$ reduction of $31.47 \%$, could be achieved. Assuming the theoretical adoption of all the GPP policies (including the ones with a high difficulty and the best option for the self-excluding cases), a net reduction of $1052 \mathrm{gCO} 2 \mathrm{eq} / \mathrm{meal}$, which corresponds to a CF reduction of $63.16 \%$, could be achieved.

\section{Policy lessons and conclusions}

This paper presents a method to assess GPP policies, with a particular focus on policies concerning food provision and catering services. It is shown that the life cycle approach, despite the complexity and uncertainty of modelling, is an essential prerequisite to developing sustainable strategies for public procurements. The adoption of the life cycle approach is essential since the evaluation of single phases or aspects may lead to incorrect or incomplete assessments. In particular, the study focuses on accounting for the GHG emissions related to different GPP policies, since this indicator may easily be understood by decision makers and citizens and since the reduction of GHG emissions represents one of the objectives of local authorities. Such an approach allows local authorities to rank and prioritise possible actions. GPP policies contributing to large CF reductions for some life cycle phases may result in a small benefit when the full catering service is considered. Moreover, procurement policies that are generally assumed to be highly relevant for some sectors (e.g. policies on transport) may not be effective for the specific service under study.

The proposed assessment of GPP policies has been applied to a case study: the school catering service of the city of Turin (Italy). GPP policies for catering were identified and successively ranked according to their potential for CF reduction. The analysis proved that the most effective policies are those affecting the production phase (although the GHG emissions of this phase are subject to a high uncertainty). In particular, the reduction of meat consumption is confirmed to have a high $\mathrm{CF}$ reduction potential, together with the shift of food production from conventional to organic agriculture.

The second main area of intervention is related to the cooking, storing, and serving procedures. For the presented case study, higher benefits could be achieved with the shift to an energy mix with a lower CF (e.g. electricity with higher shares of renewable energy sources) rather than with the purchasing of more efficient appliances. However, this conclusion is affected by high uncertainty due to the estimation of the energy-saving potential of professional appliances. The 
development of energy labelling schemes for such appliances could be a relevant target for future policy actions.

The third area of improvement in terms of CF concerns policies targeting waste, including both prevention and management. Several different options could be implemented, together bringing a significant reduction in CF.

Options related to the logistics of food, regarding both long distance transport and urban distribution, were less relevant for this analysis. However, it is recognised that GPP policies on transport and food origin could be potentially relevant for other aspects, such as to support local food production and the local economy, to defend traditional local products and to preserve agricultural biodiversity, and to reduce the impacts of transport and the pollution of cities (for example the use of natural gas vans for the urban distribution could have a positive impact on the urban air quality). This leads to the possibility of comparing different procurement options based on different impacts. Indeed, the methodological approach used in the current study is flexible enough to be adapted to other life cycle impact categories.

It is interesting to assess the effectiveness of the policies versus the efforts and costs required to enforce them. Indeed, procurement policies regarding food production are more effective but more difficult to implement. On the other hand, policies regarding waste have a lower improvement potential but also those require less effort (most of the time focusing on the adoption of good practices and on the proper training of the operators).

The proposed assessment method, here applied to a specific case of restoration, can be applied not only to other public food services, such as hospitals, but also to private catering services for canteens, restaurants, and bars. In these cases, the use of proxies can also be significant. However, it is necessary to assess whether it is preferable to carry out the LCA of certain foods rather than considering generic proxies, because of the lower number of annual meals.

Furthermore, because of the need to consider several stages of the catering service, simplified LCA-based tools, specific to collective restoration systems, can support both managers (public or private) and suppliers. These tools should be usable without the need of experts so that they may be included in calls for tenders together with other factors, such as the price and the quality of food. It is recognised that an assessment based on a singleindicator approach is accompanied by some uncertainty, since it could hide some offsets of impacts among different life cycle stages, leading to the selection of nonoptimal policy strategies. For this reason, future developments of the method should focus on the quantification of additional impact categories, producing results that can be still interpreted by non-LCA experts and that do not require too burdensome calculations.
Acknowledgments This research was financed as part of the project "INNOCAT-procurement of eco-innovation in the catering sector", called "ENT/CIP/11/C/N02C00 Reinforcing procurement of eco-innovation-network of green public and private procurers" of CUP C15J13000000001. The authors gratefully acknowledge Dr. Filippo Valfrè, Dr. Mariangela De Piano, and her team at the Restoration Management Office of the city of Turin for their fundamental support in the data gathering and revision of the analysis. The authors also acknowledge the great support of Dr. Elena Deambrogio of the European Policies and Innovation Office of the city of Turin.

Disclaimer The information and views set out in this publication are those of the authors and do not necessarily reflect the official opinion of the city of Turin, Italy. Neither the offices or bodies of the city of Turin nor any person acting on their behalf may be held responsible for the use which may be made of the information contained herein.

Open Access This article is distributed under the terms of the Creative Commons Attribution 4.0 International License (http:// creativecommons.org/licenses/by/4.0/), which permits unrestricted use, distribution, and reproduction in any medium, provided you give appropriate credit to the original author(s) and the source, provide a link to the Creative Commons license, and indicate if changes were made.

\section{References}

Agri ISTAT (2015) Electronic information system on agriculture and livestock. Italian National statistical Institute (ISTAT), Rome. Available from: http://agri.istat.it/ Accessed: 16 March 2015

Allacker K, Mathieux F, Manfredi S, Pelletier N, De Camillis C, Ardente F, Pant R (2014) Allocation solutions for secondary material production and end of life recovery: proposals for product policy initiatives. Resour Conserv Recy 88:1-12

Alvarez RA, Pacala SW, Winebrake JJ, Chameides WL, Hamburg SP (2012) Greater focus needed on methane leakage from natural gas infrastructure. Proc Natl Acad Sci 109(17):6435-6440

Ardente F, Mathieux F (2014) Environmental assessment of the durability of energy-using products: method and application. J Clean Prod 74(1):62-73

Baldo GL, Marino M, Montani M, Ryding SO (2009) The carbon footprint measurement toolkit for the EU ecolabel. Int J Life Cycle Assess 14(7):591-596

Baldwin C, Wilberforce N, Kapur A (2011) Restaurant and food service life cycle assessment and development of a sustainability standard. Int J Life Cycle Assess 16(1):40-49

Barling D, Andersson G, Bock B, Canjels A, Galli F, Gourlay R, Hoekstra F, de Iacovo F, Karner S, Mikkelsen BE, Selunda A, Smith J, Sonnino R (2013) Revaluing public sector food procurement in Europe: an action plan for sustainability http://uhra.herts.ac. uk/handle/2299/16436 (accessed 08.09.2015)

Baumann H, Tillman AM (2004) The hitch hiker's guide to LCA. An orientation in life cycle assessment methodology and application. Studentlitteratur $\mathrm{AB}$

Bertoldi P, Atanasiu B (2009) Electricity consumption and efficiency trends in European Union - status report 2009. JRC-IE, Ispra

Bobba S, Ardente F, Mathieux F (2016) Environmental and economic assessment of durability of energy-using products: method and application to a case-study vacuum cleaner. J Clean Prod 137:762-776

Bortolini M, Faccio M, Ferrari E, Gamberi M, Pilati F (2016) Fresh food sustainable distribution: cost, delivery time and carbon footprint three-objective optimization. J Food Eng 174:56-67

British Standards Institution (BSI) (2011) Publicly available specification (PAS) 2050 - specification for the assessment of the life cycle greenhouse gas emissions of goods and services 
Capaccioni B, Caramiello C, Tatàno F, Viscione A (2011) Effects of a temporary HDPE cover on landfill gas emissions: multiyear evaluation with the static chamber approach at an Italian landfill. Waste Manag 31(5):956-965

Caputo P, Ducoli C, Clementi M (2014) Strategies and tools for ecoefficient local food supply scenarios. Sustainability 6(2):631-651

Cellura M, Ardente F, Longo S (2012) From the LCA of food products to the environmental assessment of protected crops districts: a casestudy in the south of Italy. J Environ Manag 93:194-208

Cerutti AK, Calvo A, Bruun S (2014a) Comparison of the environmental performance of light mechanization and animal traction using a modular LCA approach. J Clean Prod 64:396-403

Cerutti AK, Beccaro GL, Bruun S, Bosco S, Donno D, Notarnicola B, Bounous G (2014b) Life cycle assessment application in the fruit sector: state of the art and recommendations for environmental declarations of fruit products. J Clean Prod 73:125-135

Cerutti AK, Contu S, Ardente F, Donno D, Beccaro GL (2016) Carbon footprint in green public procurement: policy evaluation from a case study in the food sector. Food Policy 58:82-93

Chandler C, Franklin A, Ochoa A, Clement S (2015) Sustainable public procurement of school catering services. A good practice report. Final report of the INNOCAT project. http:/www.sustainablecatering.eu/fileadmin/user_upload/enewsletter/Documents/ INNOCAT_Catering_Report_FINAL.pdf

Chen WT, Hsu CI (2015) Greenhouse gas emission estimation for temperature-controlled food distribution systems. J Clean Prod 104:139-147

Clune S, Crossin E, Verghese K (2016) Systematic review of greenhouse gas emissions for different fresh food categories. J Clean Prod 140(2):766-783

De Almeida A, Fonseca P, Schlomann B, Feilberg N (2011) Characterization of the household electricity consumption in the EU, potential energy savings and specific policy recommendations. Energ Buildings 43(8):1884-1894

Eberle U, Fels J (2016) Environmental impacts of German food consumption and food losses. Int J Life Cycle Assess 21(5):759-772

EPD (2008) Environmental Product Declaration of Servizio di Captazione, Disinfezione e Distribuzione di Acqua da Sorgente ad uso potabile per il Comunedi Lizzano in Belvedere. Registration Number: S-EP-00038. Accessed 05.09.2014 on http://www. environdec.com/

European Commission (2000) Regulation (EC) no. 1980/2000 of the European Parliament and of the council of 17 July 2000 on a revised community ecolabel award scheme. OJEC L237(1):1-12

European Commission (2010) Regulation (EC) no. 66/2010 of the European Parliament and of the council of 25 November 2009 on the EU ecolabel (text with EEA relevance). OJEC L27:1-19

European Commission (2011) Buying green! A handbook on green public procurement, 2nd edn. Publications Office of the European Union, Luxembourg

Falasconi L, Vittuari M, Politano A, Segrè A (2015) Food waste in school catering: an Italian case study. Sustainability 7(11):14745-14760

Fang K, Heijungs R, De Snoo GR (2014) Theoretical exploration for the combination of the ecological, energy, carbon, and water footprints: overview of a footprint family. Ecol Ind 36:508-518

Fang K, Heijungs R, De Snoo GR (2015) Understanding the complementary linkages between environmental footprints and planetary boundaries in a footprint-boundary environmental sustainability assessment framework. Ecol Econ 114:218-226

FERCO (European Federation of Contract Catering Organisations) (2012), The European contract catering sector and the future of the VAT regime, available at: http://www.foodserviceeurope.org/ gallery/58/Briefing \%20Paper \%20on \%20VAT \%20and $\% 20$ Catering \%20(August \%202012).pdf, (accessed 15th Mar 2016)
Finkbeiner M (2009) Carbon footprinting —opportunities and threats. Int J Life Cycle Assess 14(2):91-94

Fusi A, Guidetti R, Azapagic A (2016) Evaluation of environmental impacts in the catering sector: the case of pasta. J Clean Prod 132: 146-160

Galatola M, Pant R (2014) Reply to the editorial "product environmental footprint - breakthrough or breakdown for policy implementation of life cycle assessment?" written by Prof. Finkbeiner (Int J Life Cycle Assess 19(2):266-271). Int J Life Cycle Assess 19(6):1356

Garnett T (2009) Livestock-related greenhouse gas emissions: impacts and options for policy makers. Envrion Sci Policy 12(4):491-503

Garnett T (2011) Where are the best opportunities for reducing greenhouse gas emissions in the food system (including the food chain)? Food Policy 36:23-S32

GIRA Foodservice (2014) The contract catering market in Europe 20092014 - 15 counties, for Food Service Europe, October 2014

Guinee JB, Heijungs R, Huppes G, Zamagni A, Masoni P, Buonamici R, Rydberg T (2010) Life cycle assessment: past, present, and future. Environ Sci Technol 45(1):90-96

Hayashi K (2013) Practical recommendations for supporting agricultural decisions through life cycle assessment based on two alternative views of crop production: the example of organic conversion. Int $\mathrm{J}$ Life Cycle Assess 18(2):331-339

Intergovernmental Panel on Climate Change (IPCC) (2007) Climate change 2007: synthesis report. Contribution of Working Groups I, II and III to the Fourth Assessment Report of the Intergovernmental Panel on Climate Change

International Organisation for Standardisation - ISO (2013) TS 14067: 2013: greenhouse gases - carbon footprint of products - requirements and guidelines for quantification and communication. International Organization for Standardization. Geneva, Switzerland

Joint Research Centre (JRC) (2010) International Reference Life Cycle Data System (ILCD) handbook - general guide for life cycle assessment-detailed guidance. First edition March 2010. EUR 24708 EN. Luxembourg. Publications Office of the European Union

Jungbluth N, Keller R, König A (2016) ONE TWO WE-life cycle management in canteens together with suppliers, customers and guests. Int J Life Cycle Assess 21(5):646-653

Lacourt I, Mariani M (2015) City food policies. Securing our daily bread in an urbanizing world. Le Château edizioni, Aosta

Latunussa CE, Ardente F, Blengini GA, Mancini L (2016) Life cycle assessment of an innovative recycling process for crystalline silicon photovoltaic panels. Sol Energ Mat Sol C 156:101-111

Laurent A, Olsen SI, Hauschild MZ (2012) Limitations of carbon footprint as indicator of environmental sustainability. Environ Sci Technol 46(7):4100-4108

López JM, Gómez Á, Aparicio F, Sánchez FJ (2009) Comparison of GHG emissions from diesel, biodiesel and natural gas refuse trucks of the City of Madrid. Appl Energy 86(5):610-615

Lou XF, Nair J (2009) The impact of landfilling and composting on greenhouse gas emissions-a review. Bioresource Technol 100(16):3792-3798

Ménard JF, Lesage P, Deschênes L, Samson R (2004) Comparative life cycle assessment of two landfill technologies for the treatment of municipal solid waste. Int J Life Cycle Assess 9(6):371-378

Mila i Canals L, Cowell SJ, Sim S, Basson L (2007) Comparing domestic versus imported apples: a focus on energy use. Environ Sci Pollut Res 14(5):338-344

Muñoz I, Mila i Canals L, Fernandez-Alba AR (2010) Life cycle assessment of the average Spanish diet including human excretion. Int $\mathrm{J}$ Life Cycle Assess 15(8):794-805

Nemecek T, Huguenin-Elie O, Dubois D, Gaillard G (2005) Ecoefficiency in arable and grassland systems. In: Piqué FC, Rieradevall i Pons J (eds) LCM2005: Innovation by Life Cycle Management, vol. 1, Barcelona, September 5-7, 2005, pp 431-436 
Nemecek T, Weiler K, Plassmann K, Schnetzer J, Gaillard G, Jefferies D, García-Suárez T, King H, Mila i Canals L (2012) Estimation of the variability in global warming potential of worldwide crop production using a modular extrapolation approach. J Clean Prod 31:106-117

Neto B, Rodríguez Quintero R, Wolf O, Sjögren P, Lee P (2016) Revision of the EU Green Public Procurement criteria for food and catering services. http://susproc.jrc.ec.europa.eu/Food_Catering/docs/EU $\% 20$ GPP \%20Food \%20Catering \%20services Technical $\% 20$ Report.pdf

Nordborg M, Davis J, Cederberg C, Woodhouse A (2017) Freshwater ecotoxicity impacts from pesticide use in animal and vegetable foods produced in Sweden. Sci Total Environ 581-582:448-459

Notarnicola B, Salomone R, Petti L, Renzulli PA, Roma R, Cerutti AK (eds) (2015) Life cycle assessment in the agri-food sector: case studies, methodological issues and best practices. Springer International Publishing, Cham

Notarnicola B, Tassielli G, Renzulli PA, Castellani V, Sala S (2017) Environmental impacts of food consumption in Europe. J Clean Prod 140:753-765

Ostrom E (2009) A polycentric approach for coping with climate change. Policy Research Working Paper 5095. (Available at SSRN: https:// ssrn.com/abstract=1934353; accessed November 2017).

Pairotti MB, Cerutti AK, Martini F, Vesce E, Padovan D, Beltramo R (2015) Energy consumption and GHG emission of the Mediterranean diet: a systemic assessment using a hybrid LCA-IO method. J Clean Prod 103:507-516

Perrin A, Basset-Mens C, Gabrielle B (2014) Life cycle assessment of vegetable products: a review focusing on cropping systems diversity and the estimation of field emissions. Int J Life Cycle Assess 19(6): $1247-1263$

Pollan M (2006) The omnivore's dilemma: a natural history of four meals. Penguin

Pulkkinen H, Roininen T, Katajajuuri JM, Järvinen M (2016) Development of a climate choice meal concept for restaurants based on carbon footprinting. Int J Life Cycle Assess 21(5):621-630

Razza F, Cerutti AK (2017) Life cycle and environmental cycle assessment of biodegradable plastics for agriculture. In: Malinconico M (ed) Soil degradable bioplastics for a sustainable modern agriculture. Springer, Berlin Heidelberg, pp 169-185

Razza F, Fieschi M, Degli Innocenti F, Bastioli C (2009) Compostable cutlery and waste management: an LCA approach. Waste Manag 29(4):1424-1433

Roy P, Nei D, Orikasa T, Xu Q, Okadome H, Nakamura N, Shiina T (2009) A review of life cycle assessment (LCA) on some food products. J Food Eng 90(1):1-10
Rojas A, Valley W, Mansfield B, Orrego E, Chapman GE, Harlap Y (2011) Toward food system sustainability through school food system change: Think\&EatGreen@ School and the making of a community-university research alliance. Sustainability 3(5):763788

Rothwell A, Ridoutt B, Page G, Bellotti W (2015) Environmental performance of local food: trade-offs and implications for climate resilience in a developed city. J Clean Prod 112:420-430

Sala S, Benini L, Crenna E, Secchi M (2016) Global environmental impacts and planetary boundaries in LCA. European Commission, Joint Research Centre - Technical Report. http://publications.jrc.ec. europa.eu/repository/handle/JRC105141

Smith J, Andersson G, Gourlay R, Karner S, Mikkelsen BE, Sonnino R, Barling D (2016) Balancing competing policy demands: the case of sustainable public sector food procurement. J Clean Prod 112:249256

Steinfeld H, Gerber P, Wassenaar T, Castel V, Rosales M, De Haan C (2006) Livestock's long shadow. FAO, Rome

Sturtewagen L, De Soete W, Dewulf J, Lachat C, Lauryssen S, Heirman B, Rossi F, Schaubroeck T (2016) Resource use profile and nutritional value assessment of a typical Belgian meal, catered or home cooked, with pork or Quorn ${ }^{\mathrm{TM}}$ as protein source. J Clean Prod 112: 196-204

United Nations Framework Convention on Climate Change (UNFCCC) (1997) Kyoto protocol to the United Nations framework convention on climate change

Vassallo M, Scalvedi ML, Saba A (2016) Investigating psychosocial determinants in influencing sustainable food consumption in Italy. Int J Consum Stud 40(4):422-434

VV. AA (1997) In: Hoepli U (ed) Manuale di Agricoltura, second edn. Italy, Milano

Weidema BP, Thrane M, Christensen P, Schmidt J, Løkke S (2008) Carbon footprint - a catalyst for life cycle assessment? J Ind Ecol 12(1):3-6

World Business Council for Sustainable Development, \& World Resources Institute (2001) The greenhouse gas protocol: a corporate accounting and reporting standard. World Resources Inst.

World Health Organization (2015) Q\&A on the carcinogenicity of the consumption of red meat and processed meat. http://www.who.int/ features/qa/cancer-red-meat/en/

World Health Organization (2013) Methods and data sources for global burden of disease estimates 2000-2011. http://www.who.int/ healthinfo/global_burden_disease/estimates/en/index $2 . h t m l$ 